\title{
Flora y vegetación del municipio Álamo Temapache, Veracruz, México
}

\section{Flora and vegetation of the municipality of Álamo Temapache, Veracruz, Mexico}

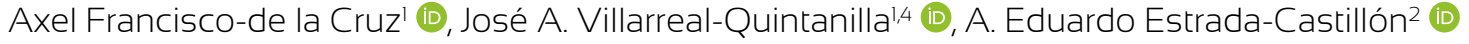 \\ y Diana Jasso-Cantú 3 (1)
}

1 Universidad Autónoma Agraria Antonio Narro, Departamento de Botánica, Calzada Antonio Narro 1923, Buenavista, 25315 Saltillo, Coahuila, México.

2 Universidad Autónoma de Nuevo León, Facultad de Ciencias Forestales, Apdo. postal 41, 67700 Linares, Nuevo León, México.

3 Universidad Autónoma Agraria Antonio Narro, Departamento de Fitomejoramiento, Calzada Antonio Narro 1923, Buenavista, 25315 Saltillo, Coahuila, México.

4 Autor para la correspondencia: javillarrealOO@hotmail.com

\section{Citar como}

Francisco-de la Cruz, A., J. A. VillarrealQuintanilla, A. E. Estrada-Castillón y D. Jasso-Cantú. 2017. Flora y vegetación del municipio Álamo Temapache, Veracruz, México. Acta Botanica Mexicana 121 83-124. DOI: http://dx.doi.org/10.21829/ abml21.2017.1291

Recibido: 26 de mayo de 2016 Revisado: 9 de junio de 2016 Aceptado: 5 de junio de 2017.

DOI:

http://dx.doi.org/10.21829/abml21.2017.1291

\section{REsUmen:}

Antecedentes y Objetivos: El objetivo del presente estudio fue conocer la flora y describir la vegetación del municipio Álamo Temapache, en el estado de Veracruz, México. El área está ubicada en el norte del estado y ocupa una extensión de $1280.62 \mathrm{~km}^{2}$.

Métodos: Se delimitó la zona y se definieron rutas de colecta y reconocimiento de los tipos de vegetación. Se tomaron datos del tipo de comunidad vegetal y componentes, y se colectaron muestras botánicas. Finalmente se elaboró un mapa de vegetación y se enlistaron las especies con datos de forma de vida, nombre común y tipo de comunidad donde fueron localizadas.

Resultados clave: Los resultados incluyen una lista florística de 753 especies, 491 géneros y 124 familias. Las familias mejor representadas son Fabaceae, Asteraceae, Poaceae y Malvaceae. Se reconocen ocho tipos de vegetación para el área: bosque tropical perennifolio, bosque tropical subcaducifolio, bosque de encino, palmar, vegetación acuática y subacuática, vegetación secundaria, comunidad de arvenses, y pastizal. Gran parte de la superficie es ocupada por huertos y campos agrícolas. La comunidad de malezas de áreas perturbadas es muy importante, en especial la de plantas arvenses, que es la que ocupa la mayor extensión en el área, seguida por el pastizal inducido y el bosque tropical subcaducifolio.

Conclusiones: Se encontró que el área ha sido modificada fuertemente por actividades antrópicas; solo $8 \%$ de la superficie del municipio aún conserva la vegetación original.

Palabras clave: bosque tropical, florística, inventario florístico, riqueza.

\section{ABSTRACT:}

Background and Aims: The aim of this study was to know the flora and to describe the vegetation of the municipality of Álamo Temapache, Veracruz. The area is located in the north of this state and covers $1280.62 \mathrm{~km}^{2}$.

Methods: A delimitation of the area was realized and collection routes for recognition of vegetation types were determined. Data of the vegetation types and components were taken and botanical samples collected. Finally, a vegetation map was made and a list of habit, common name and vegetation type for each species was elaborated.

Key results: The results show a floristic list of 753 species, 491 genera and 124 families. The families with highest species numbers are Fabaceae, Asteraceae, Poaceae and Malvaceae. Eight vegetation types are recognized for the area: tropical evergreen forest, tropical deciduous forest, oak forest, palm forest, subaquatic and aquatic vegetation, secondary vegetation, weed community, and grassland. Most of the area is occupied by orchards and farmland. The weed community is the most extensive in the area, followed by induced grassland and tropical deciduous forest.

Conclusions: The area has been radically changed by anthropic activities, only $8 \%$ of the original vegetation remains.

Key words: floristic, floristic list, richness, tropical forest. 


\section{INTRODUCCIÓN}

En el territorio mexicano se encuentran casi todos los tipos de vegetación reconocidos en el mundo, existiendo además una alta diversidad de especies (Rzedowski, 1991). A nivel mundial se le considera un país megadiverso y desde el punto de vista florístico ocupa el cuarto lugar, ya que cuenta entre 21,841 a 26,495 especies de plantas fanerógamas (CONABIO, 2014; Villaseñor y Ortiz, 2014), cifras que podrían variar, ya sea por los nuevos registros, o bien por aquellas especies que se extingan (Flores-Villela y Gerez-Fernández, 1994).

En cuanto a riqueza florística, Veracruz es uno de los estados con mayor número de especies junto con Oaxaca, Chiapas, Jalisco y Guerrero (Villaseñor y Ortiz, 2014), registrándose a la fecha cerca de 8400 , además de una gran variación paisajista y cultural (Castillo-Campos et al., 2011). El estado presenta también un gran número de tipos de vegetación y ecosistemas registrados para México que van desde los de alta montaña hasta los de zonas costeras (Vázquez-Torres et al., 2010). Cerca de 50\% de las especies en el estado son hierbas, debido probablemente a la gran perturbación que ha avanzado en más de $85 \%$ ocasionando que varios tipos de vegetación estén en riesgo de desaparecer completamente. Más de 400 especies de plantas están en riesgo de las cuales, cerca de $25 \%$ son endémicas al estado (Castillo-Campos et al., 2011).

El conocimiento y análisis de la diversidad biológica es fundamental para determinar la estructura y función de las comunidades (Cruz-Elizalde y Ramírez-Bautista, 2012), resultando muy conveniente y útil en la valoración de la biodiversidad (Moreno, 2001). De esta manera, es prioritario contar con información actualizada del registro de especies, así como de su estado de conservación. Por otra parte, los estudios de vegetación constituyen una herramienta fundamental en la planeación territorial, sobre el uso y manejo de los recursos naturales y su sustentabilidad (Riba, 1993).

En México, el conocimiento florístico y de sus comunidades vegetales es aún incompleto puesto que quedan muchas áreas inexploradas donde la información florística es escasa. El acelerado desarrollo urbano no planificado ha restado gradualmente superficie a los ecosistemas; este desarrollo, aunado a las áreas cultivadas, ha impactado severamente en áreas de vegetación nativa como vegetación de galería, selvas, bosque de encinos, manglares y otros (Benítez et al., 2004). El estado de Veracruz es quizá uno de los estados del país con más deterioro ambiental y presenta el reto de proteger lo poco que aún queda y restaurar algunos ecosistemas en peligro de desaparición (Castillo-Campos et al., 2003).

El municipio Álamo Temapache no escapa a esos problemas y carece de un conocimiento actualizado de su flora. Sin embargo, existen algunos trabajos importantes relacionados con el área de estudio como el de Puig (1974), en la Huasteca, que incluye la parte norte del estado de Veracruz, donde se clasificó la vegetación de manera general y se realizó un listado florístico. Martínez y Ojeda (1977) realizaron en la parte sur del estado de Tamaulipas un estudio florístico. Basáñes et al. (2008) mencionan la composición florística y estructura arbórea de la selva mediana subperennifolia en el ejido "El Remolino", en Papantla, Veracruz. Otro trabajo es el de Gutiérrez-Báez (1993) que presenta una lista florística de los municipios de Pánuco, Pueblo Viejo y Tampico Alto; además, clasifica la vegetación en selva baja espinosa, selva mediana subcaducifolia, encinar de Quercus oleoides y vegetación acuática con seis comunidades: dunas, hidrófitas libremente flotantes, hidrófitas flotantes arraigadas al fondo, hidrófitas emergentes, riparia y manglar.

Ante las amenazas de daño ambiental que enfrenta el municipio Álamo Temapache, el presente trabajo tiene como objetivo documentar la riqueza florística, las formas biológicas de su flora y describir la vegetación y su distribución dentro de este municipio, contribuyendo al conocimiento de los recursos naturales del estado de Veracruz.

\section{Materiales y Métodos}

\section{Área de estudio}

El municipio Álamo Temapache se encuentra en la zona norte del estado de Veracruz, limita al norte con los municipios de Tepetzintla, Cerro Azul y Tamiahua, al este con 
Tuxpan, al sur con Tihuatlán, Castillo de Teayo y el estado de Puebla, al suroeste con Ixhuatlán de Madero y al oeste con Chicontepec (Fig. 1). Se ubica en la región Huasteca Baja, entre los paralelos $20^{\circ} 47^{\prime}$ y $21^{\circ} 12^{\prime} \mathrm{N}$ y los meridianos $97^{\circ} 30^{\prime}$ y $97^{\circ} 56^{\prime} \mathrm{W}$, con una altitud entre 10 y $500 \mathrm{~m}$ (SEFIPLAN, 2014). Ocupa una superficie de $1280.62 \mathrm{~km}^{2}$, cifra que representa $1.8 \%$ de la del estado (INEGI, 2014).

El clima, de acuerdo con la clasificación de Köppen adaptada para el territorio mexicano por García (1998), es cálido húmedo (Am) y cálido subhúmedo (Aw); se presentan lluvias abundantes en los meses de junio a septiembre. La temperatura máxima anual es de $39^{\circ} \mathrm{C}$ y la mínima de
$12{ }^{\circ} \mathrm{C}$ y su precipitación pluvial media anual es de 1091 $\mathrm{mm}$. Este municipio pertenece a la provincia florística de la Costa del Golfo de México, que se extiende a lo largo de los estados de Veracruz y Tabasco y áreas vecinas, con clima cálido y dominancia de vegetación tropical (Rzedowski, 1978). Los suelos son de tipo Feozem, Regosol y Vertisol (SEFIPLAN, 2009). Se ubica en la cuenca del río Tuxpan cuya corriente nace en el estado de Hidalgo con el nombre del río Pantepec, a una elevación de 2750 m s.n.m., que al confluir con el río Vinazco es conocido como río Tuxpan y desemboca en el Golfo de México, en el municipio Tuxpan (Rosas-Sánchez, 2011).
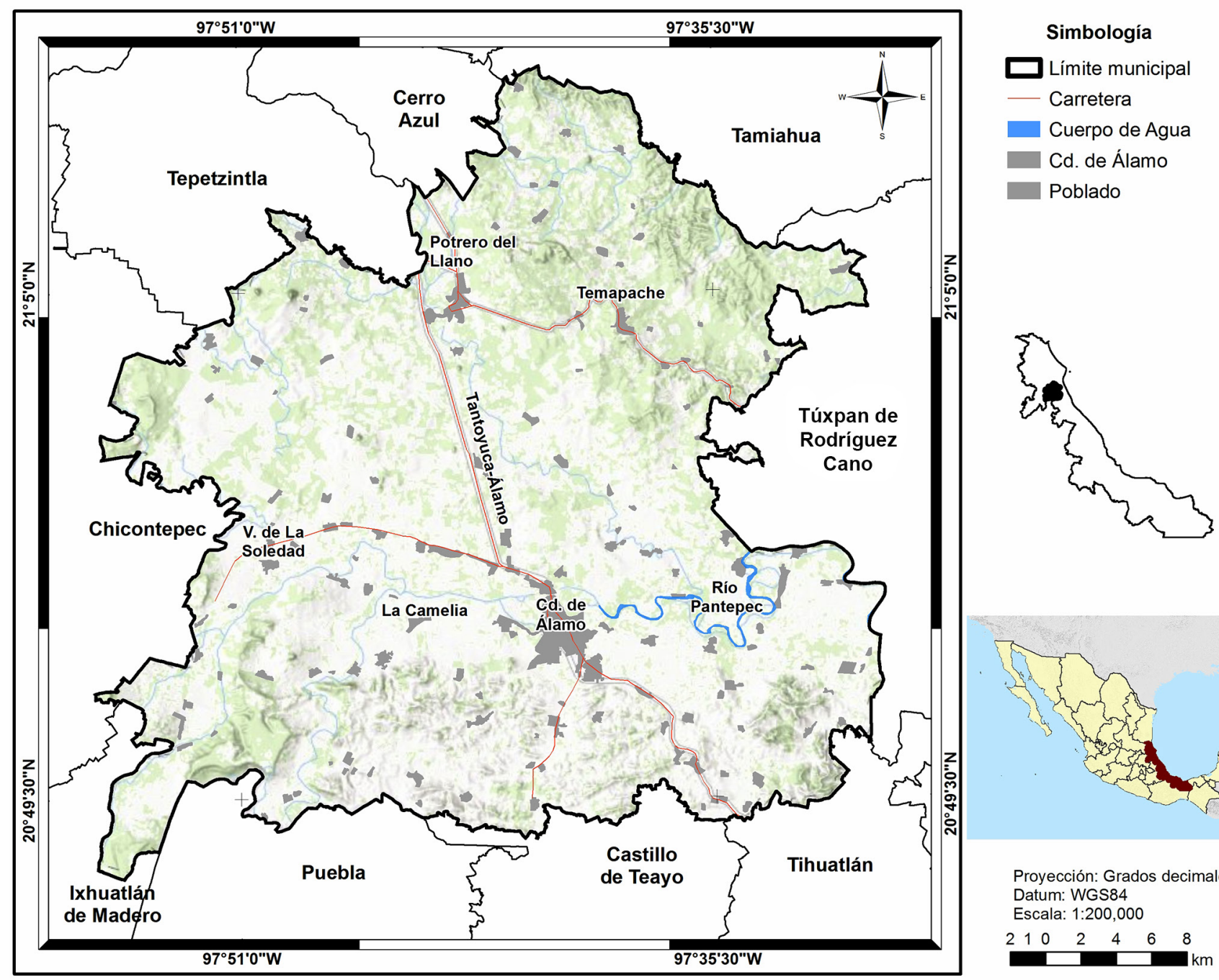

Figura 1: Mapa de ubicación del municipio Álamo Temapache, Veracruz. 


\section{Trabajo de gabinete}

Con el apoyo de fotografías aéreas blanco y negro escala 1: 50 000, el portal de internet del servidor público y gratuito Google Earth y las cartas topográficas F14D45, F14D54 y F14D55 del Instituto Nacional de Geografía y Estadística (INEGI, 2013), se delimitó el área de estudio. Posteriormente se definieron rutas de colecta y reconocimiento, asegurándose que abarcasen los diferentes tipos de comunidades vegetales y ambientes detectados en el mapa de vegetación escala 1: 180000 del Instituto Nacional de Geografía y Estadística (INEGI, 2013).

\section{Trabajo de campo}

Con el propósito de documentar el mayor número de especies de la flora vascular, se recolectaron muestras de plantas y se registró la presencia de las especies en los diferentes tipos de vegetación, durante los años 2013 y 2014 en las cuatro estaciones del año. Los recorridos de colecta se determinaron en trayectos que incluyeran varios tipos de vegetación. Se realizaron 18 salidas al campo y 22 recorridos, considerándose al menos dos visitas por tipo de vegetación. Los datos de colecta incluyen el sitio en la comunidad vegetal, plantas asociadas, forma de vida, datos de altitud y coordenadas. El material se herborizó de acuerdo al método descrito por Sánchez-González y González-Ledezma (2007), y se depositó en el herbario ANSM de la Universidad Autónoma Agraria "Antonio Narro", ubicado en la ciudad de Saltillo, Coahuila. Los duplicados fueron distribuidos a otros herbarios, principalmente MEXU y CIIDIR. La determinación de las muestras herborizadas se llevó a cabo mediante la utilización de las Floras de Veracruz, del Bajío y de Regiones Adyacentes y del Valle de Tehuacán-Cuicatlán, comparándose con otros ejemplares de herbario y confirmándose con especialistas en diferentes grupos.

Se elaboraron listas parciales para cada una de las agrupaciones vegetales, con las cuales se preparó una matriz de datos en Excel, que sirvió de base para preparar el listado florístico total (Apéndice). Los nombres científicos están citados de acuerdo a las bases de datos de Tropicos del Missouri Botanical Garden (TROPICOS, 2015) y The
Plant List del Real Jardín Botánico de Kew (The Plant List, 2015). Las categorías de familia, género y especie se arreglan alfabéticamente en el listado y la clasificación sigue el criterio propuesto por APG IV (APG, 2016).

Para establecer en forma preliminar los tipos de vegetación en el área de estudio se emplearon las cartas de uso de suelo de la serie 5 (INEGI, 2013). En campo se establecieron 25 puntos de control para verificar la información de las cartas y crear un mapa de vegetación en base a datos reales y actualizados. En el reconocimiento de los tipos de vegetación se aplicó el criterio fisionómico-florístico presentado por Rzedowski (1978) y la guía de interpretación de cartografía de uso del suelo y vegetación (INEGI, 2009).

Por medio del paquete informático QGIS 2.6 Brighton (2014) se elaboró un mapa escala 1: 200000 de vegetación y uso del suelo del municipio. Se empleó la proyección en grados decimales (Datum: WGS84), luego se digitalizó sobre la imagen de satélite de Google Earth a una escala de 1: 4000, lo que permitió generar una capa de polígonos, información con la cual se configuró un mapa de vegetación.

\section{Resultados}

\section{Flora}

Se registraron para el municipio 753 especies, distribuidas en 491 géneros pertenecientes a 124 familias (Cuadro 1), de un total de 1450 números de colecta. La lista completa se presenta en el Apéndice. Las Pteridophyta están representadas por 21 especies $(2.78 \%)$ del total del listado y las Pinophyta por tres $(0.39 \%)$. En las Magnoliophyta, las Magnolides conforman 2.12\%, las Monocotiledóneas $21.5 \%$ y las Eudicotiledóneas $73.1 \%$, siendo estas últimas las más numerosas. Se localizaron siete especies listadas en la NOM-059-SEMARNAT-2010 (SEMARNAT, 2010). Dos se encuentran en la categoría "En Peligro de extinción": 1) la "palma de la virgen" (Dioon edule Lindl.), cuya distribución se restringe a peñascos o laderas pronunciadas del bosque tropical subperenifolio y subcaducifolio y 2) Cedrela odorata L., el "cedro rojo", "Sujeta a pro- 
Cuadro 1: Representación de la flora vascular en el municipio Álamo Temapache, Veracruz.

\begin{tabular}{llccc}
\hline División & Clase & Familias & Géneros & Especies \\
\hline Pteridophyta (Helechos y afines) & & 10 & 16 & 21 \\
Pinophyta (Gymnospermas) & & 3 & 3 & 3 \\
Magnoliophyta (Angiospermas) & Magnolides & 5 & 11 & 16 \\
& Monocotiledóneas & 22 & 93 & 162 \\
& Eudicotiledóneas & 84 & 368 & 551 \\
Totales & & 124 & 491 & 753 \\
\hline
\end{tabular}

tección especial", se le encuentra como árboles aislados en potreros y áreas de cultivo y en ocasiones cultivada. Cuatro especies están en la categoría de "Amenazadas:" 1) Astronium graveolens Jacq., 2) Bravaisia integerrima (Spreng.) Standl., 3) Chamaedorea elegans Mart. y 4) Chamaedorea ernesti-augusti $\mathrm{H}$. Wendl., distribuidas en el bosque tropical perennifolio.

En el Cuadro 2 se enlistan los datos de las familias más numerosas y se comparan con la información a nivel nacional. El análisis de la riqueza de géneros y especies por familia en el municipio permitió conocer que las más numerosas son Fabaceae (39 géneros/70 especies), Asteraceae (43/52), Poaceae (30/52), Malvaceae (27/38), Euphorbiaceae (14/35), Solanaceae (10/19), Rubiaceae (12/17), Apocynaceae (13/16), Bignoniaceae (10/10), Lamiaceae (9/15), Acanthaceae (9/14) y Verbenaceae $(9 / 14)$. Este conjunto concentra $50 \%$ del total de especies encontradas. Respecto a las formas de crecimiento,

Cuadro 2: Familias de plantas mejor representadas en el municipio Álamo Temapache, Veracruz.

\begin{tabular}{lccccc}
\hline Familia & Géneros & Especies & $\begin{array}{c}\text { Géneros en } \\
\text { México }\end{array}$ & $\begin{array}{c}\text { Número de especies } \\
\text { en México }\end{array}$ & $\begin{array}{c}\text { Porcentaje géneros/spp. } \\
\text { en Álamo Temapache }\end{array}$ \\
\hline Asteraceae & 43 & 52 & 346 & $3021^{1}$ & $12.4 / 1.7$ \\
Fabaceae & 39 & 70 & 135 & $1724^{2}$ & $28.8 / 4.0$ \\
Poaceae & 30 & 52 & 166 & $1187^{1}$ & $18 / 4.3$ \\
Malvaceae & 27 & 38 & 55 & $382^{3}$ & $49 / 9.9$ \\
Euphorbiaceae & 14 & 35 & 43 & $782^{4}$ & $32.5 / 4.4$ \\
Apocynaceae & 13 & 16 & 50 & $385^{6}$ & $26 / 4.1$ \\
Rubiaceae & 12 & 17 & 93 & $593^{1}$ & $12.9 / 2.8$ \\
Solanaceae & 10 & 19 & 33 & $430^{1}$ & $30.3 / 4.4$ \\
Bignoniaceae & 10 & 10 & 27 & $80^{7}$ & $37 / 12.5$ \\
Lamiaceae & 9 & 15 & 31 & $530^{1}$ & $29 / 2.8$ \\
Acanthaceae & 9 & 14 & 39 & $400^{5}$ & $23 / 3.5$ \\
Verbenaceae & 9 & 14 & 26 & $286^{8}$ & $34.6 / 4.8$ \\
\hline
\end{tabular}

Fuente: ${ }^{1}$ Villaseñor, 2004; ${ }^{2}$ Sousa y Delgado, 1998; ${ }^{3}$ Fryxell, 1998; ${ }^{4}$ Steinmman, 2002; ${ }^{5}$ Daniel, 1992; ${ }^{6}$ Juárez-Jaimes et al., 2007; ${ }^{7}$ Martínez y Ramos, 2012; ${ }^{8}$ Willmann et al., 2000. 
las hierbas fueron las más abundantes con $44.35 \%$, donde Asteraceae y Poaceae son las familias que contribuyeron con el mayor número de especies. Los arbustos representan $21.11 \%$, en los que Euphorbiaceae, Rubiaceae y Malvaceae aportan el más alto número de elementos. Los árboles contribuyen con $15.67 \%$, con las familias más importantes: Fabaceae y Euphorbiaceae. Los bejucos apor$\tan 12.88 \%$, con amplia representación de Apocynaceae, Bignoniaceae y Fabaceae. Las epífitas agrupan 5.04\%, con mayores registros de las familias Bromeliaceae y Orchidaceae. Las parásitas contribuyen con $0.92 \%$ donde sobresalen Loranthaceae y Santalaceae.

La evaluación de la distribución de las especies por tipos de vegetación para el municipio revela que la comunidad vegetal de malezas arvenses registra el mayor número de especies (364), seguidos por el bosque tropical subcaducifolio (282), vegetación secundaria (241), bosque tropical perennifolio (228), palmar (118), vegetación acuática y subacuática (210) bosque de encino (207), y pastizal (199).

\section{Vegetación}

El área ha sido modificada radicalmente por actividades antrópicas dado que solo $8.23 \%$ de la superficie cuenta con vegetación original, por lo que en la actualidad solo quedan áreas relicto. Se reconocieron siete tipos de vegetación, basados en la nomenclatura utilizada por Rzedowski (1978): bosque tropical perennifolio, bosque tropical subcaducifolio, bosque de Quercus, pastizal inducido, vegetación acuática y subacuática, palmar, vegetación secundaria, además de las comunidades de malezas.

El bosque tropical perennifolio presenta una estructura compleja, los árboles dominantes miden entre 20 y 30 metros de alto y durante todo el año conservan las hojas. Se presenta una gran cantidad de bejucos y plantas epifitas, mientras que los estratos arbustivo y herbáceo son escasos. Este tipo de vegetación ocupa una superficie aproximada de 1302 ha, lo cual representa cerca de 1\% del territorio municipal. Se localiza en laderas y barrancas en cerros del Noreste y Suroeste del área de estudio y se encuentra severamente fragmentado y entremezclado con el bosque tropical subcaducifolio. Se desarrolla sobre suelos aluviales profundos y bien drenados, aunque también pueden llegar a inundarse. Los árboles tienen troncos rectos con contrafuertes y copas más o menos esféricas. Algunos de los más frecuentes son Astronium graveolens, Manilkara zapota (L.) P. Royen, Swietenia macrophylla King, Oreopanax guatemalensis (Lem. ex Bosse) Decne. \& Planch., Robinsonella mirandae Gómez-Pompa, Spondias mombin L., Ficus pertusa L. f., Brosimum alicastrum Sw. y Trichilia havanensis Jacq. Los arbustos más comunes son Bunchosia biocellata Schltdl., Forestiera rhamnifolia Griseb., Plumbago auriculata Lam. y Piper auritum Kunth. Los bejucos más abundantes son Cissampelos tropaeolifolia DC., Turbina corymbosa (L.) Raf., Hiraea fagifolia (DC.) A. Juss., Dioscorea convolvulacea Schltdl. \& Cham. y Heteropterys brachiata (L.) DC., entre otras. Las epifitas más frecuentes son Tillandsia spp., Monstera spp., Rhipsalis baccifera (Sol.) Stearn, Stelis ciliaris Lindl. y Epidendrum stamfordianum Bateman. En el estrato herbáceo destacan Begonia cucullata Willd., Chamaedorea elegans, Syngonium sagittatum G.S. Bunting, Lasiacis ruscifolia (Kunth) Hitchc., Heliconia schiedeana Klotzsch, Maranta arundinacea L., Pteris vittata L. y Tectaria heracleifolia (Willd.) Underw.

El bosque tropical subcaducifolio se caracteriza por la pérdida de follaje de un gran número de los elementos arbóreos. Los árboles de esta comunidad son de dosel cerrado, de 12 a $20 \mathrm{~m}$ de alto, un estrato arbustivo de 3 a $6 \mathrm{~m}$ y un herbáceo esparcido de hasta $1.5 \mathrm{~m}$. Comparte muchas características en fisionomía y en requerimientos climáticos con el bosque tropical perennifolio. Ocupa unas 6333 ha, que representan $4.9 \%$ del área. Se distribuye sobre zonas altas de los cerros como pequeños relictos aislados de vegetación natural. Los suelos son muy someros con drenaje rápido debido a la fuerte pendiente de los terrenos. Los elementos arbóreos más frecuentes son Castilla elastica Sessé, Spondias mombin, Oreopanax guatemalensis, Guazuma ulmifolia Lam., Piscidia carthagenensis Jacq., Bursera simaruba (L.) Sarg., Ceiba pentandra (L.) Gaertn., Brosimum alicastrum y Dendropanax arboreus (L.) Decne. \& Planch. Los bejucos son 
abundantes, sobre todo en zonas perturbadas, algunos de los más comunes son Agdestis clematidea Moc. \& Sessé ex DC., Ipomoea squamosa Choisy, Canavalia villosa Benth., Paullinia fuscescens Kunth, Dolichandra unguiscati (L.) L.G. Lohmann y Urvillea ulmacea Kunth, entre otras. Epífitas comunes son Vittaria lineata (L.) Sm., Tillandsia schiedeana Steud., Epidendrum stamfordianum, Monstera deliciosa Liebm. y Syngonium neglectum Schott. Se localizaron en esta comunidad dos plantas parásitas: Psittacanthus rhynchacanthus (Benth.) Kuijt y Bdallophytum americanum (R.Br.) Eichler ex Sloms, esta última parasitando a Protium copal (Schltdl. \& Cham.) Engl. Las formas arbustivas más frecuentes son Justicia brandegeeana Wassh. \& L.B. Sm., Eugenia capuli (Schltdl. \& Cham.) Hook. \& Arn., Piper auritum, Pisonia aculeata L., Randia armata (Sw.) DC., Odontonema nitidum (Jacq.) Kuntze y Chamaedorea tepejilote Liebm. El estrato herbáceo está formado usualmente por Calea urticifolia (Mill.) DC., Vernonia arctioides Less., Maranta gibba Sm., Chromolaena odorata (L.) R.M. King \& H. Rob., Leptochloa scabra Nees y Pteris vittata.

El bosque de encino se caracteriza por estar formado por un estrato arbóreo de 6 a $15 \mathrm{~m}$ de alto, dominado por elementos del género Quercus L., un arbustivo de 1 a $5 \mathrm{~m}$, de escaso a denso y un herbáceo más o menos denso de plantas de 10-30 cm de alto. Es una comunidad fragmentada que ocupa una superficie cercana a las 264 ha, que representa cerca de $0.2 \%$ de territorio del municipio. La mayor superficie se localiza en el Llano del Tigre; otras pequeñas áreas aisladas están cercanas a los poblados de Buena Vista, Hermenegildo Galeana, Ojital Ciruelo, Tierra Blanca y Potrero del Llano. Los suelos son arcillosos y someros, sobre roca basáltica, con mal drenaje y fácilmente inundables en temporada de lluvias. La especie arbórea dominante es el encino blanco (Quercus oleoides Schltdl. \& Cham.). Además, se pueden encontrar frecuentemente árboles como Bursera simaruba, Castilla elastica, Piscidia carthagenensis, Cedrela odorata, Enterolobium cyclocarpum (Jacq.) Griseb. y Coccoloba barbadensis Jacq. En el estrato arbustivo destacan Randia armata, $R$. obcordata S. Watson, Bromelia karatas
L., B. pinguin L., Acacia cornigera (L.) Willd., Xylosma flexuosa (Kunth) Hemsl. y Croton cortesianus Kunth. El componente herbáceo es abundante, principalmente en claros del bosque. Algunas de las especies más evidentes son Calea urticifolia, Brachiaria distachya (L.) Stapf, Desmodium tortuosum (Sw.) DC., Triumfetta lappula L., Malvastrum americanum (L.) Torr. y Andropogon bicornis L.

La vegetación acuática y subacuática está conformada por vegetación riparia, popal, tular y carrizal, y vegetación flotante sumergida. A continuación, se presenta cada una de ellas.

a) La vegetación riparia está formada por una serie de comunidades vegetales que se desarrollan en el margen de cuerpos y corrientes de agua, por lo general no mayores a los $300 \mathrm{~m}$ de ancho. En estos hábitats se presentan comunidades formadas por árboles de copa media, un estrato arbustivo denso y un estrato herbáceo abundante. Ocupa una superficie aproximada de 1998 ha, equivalente a cerca de 1.5\% de la superficie municipal. Se encuentra sobre los márgenes del río Pantepec, principal río que recorre el municipio de oeste a este. Esta vegetación se presenta también sobre arroyos, canales y remansos del mismo. Se ubica sobre suelos aluviales, en áreas planas o con pendientes suaves de 1 a $25 \%$. La composición del estrato arbóreo está constituida generalmente por Salix humboldtiana Willd., Populus mexicana Wesm. ex DC., Ficus insipida Willd., Maclura tinctoria (L.) D. Don ex Steud., Pithecellobium dulce (Roxb.) Benth. e Inga vera Willd. El estrato arbustivo está formado por plantas de 30 a $150 \mathrm{~cm}$ de alto, las especies más frecuentes son Arundo donax L., Piper amalago L., Solanum erianthum D. Don, Costus pulverulentus C. Persl, Ricinus communis L. y Cnidoscolus multilobus (Pax) I.M. Johnst. Dentro de las herbáceas más frecuentes se encuentran Paspalum distichum L., Acmella repens (Walter) Rich. ex. Pers., Ludwigia octovalvis (Jacq.) P.H. Raven, Lobelia cardinalis L. y Potamogeton foliosus Raf.

b) El popal está formado por plantas enraizadas en el suelo que emergen del agua por inundación (Rzedowski, 
1978). Este tipo de vegetación cubre superficies pantanosas, de agua dulce estancada o de poca corriente, de 0.5 a $1 \mathrm{~m}$ de profundidad. Todas las plantas son herbáceas de 1 a $3 \mathrm{~m}$ de alto; en el municipio se encuentran a orillas de pequeños esteros o canales artificiales, ocupando entre una a dos hectáreas. Las especies más frecuentes son Eichhornia crassipes (Mart.) Solms, Thalia geniculata L., Alisma subcordatum Raf., Maranta arundinacea, Pontederia sagittata C. Presl y Canna glauca L.

c) El tular y carrizal están constituidos por agrupaciones densas de plantas acuáticas, enraizadas en el fondo poco profundo de cuerpos de agua de corriente lenta o estacionarios, formadas fundamentalmente por especies de hojas largas y angostas (monocotiledóneas), alcanzando los tres metros y una densidad alta. Su distribución en el municipio es discontinua, rara vez sobrepasan una hectárea de cobertura. Es frecuente que una especie sea dominante excluyendo a cualquier otra, recibiendo el nombre de acuerdo al género que lo habita: tular formado por Typha domingensis Pers. y carrizal formado por Arundo donax, especie dominante que crece a orillas de río o en lugares con humedad.

d) La vegetación flotante y sumergida, que agrupa las plantas acuáticas que flotan o se mantienen normalmente por debajo de la superficie del agua, se encuentra en pequeños cuerpos de agua estancada o con corriente lenta, no sobrepasando 1.5 metros de profundidad y una hectárea de extensión. Entre las especies más comunes están Pistia stratiotes L., Eichhornia crassipes, Nelumbo lutea Willd., Nymphaea alba L., Nymphoides peltata (S.G. Gmel.) Kuntze, Lemna aequinoctialis Welw. y Marsilea macropoda Engelm. ex A. Braun. La vegetación sumergida comprende vegetales arraigados o sin fijarse al substrato, que se mantienen debajo de la superficie de agua, como Potamogeton foliosus, entre los más frecuentes.

El palmar es la comunidad dominada por Sabal mexicana Mart., que presenta una distribución discontinua, ocupando una superficie cercana a 334 ha. Usualmente se le encuentra cercana a poblados, al parecer es favorecida por actividades antrópicas, ocupa solo cerca de $0.02 \%$ de superficie del municipio. Por su fisonomía, el palmar es un bosque de hasta 15 metros de alto, con abundancia de la palma (Sabal mexicana), con árboles esporádicos de Piscidia carthagenensis, Guazuma ulmifolia, Cedrela odorata, Bursera simaruba, Enterolobium cyclocarpum, Leucaena leucocephala (Lam.) de Wit, Dendropanax arboreus y Pithecellobium dulce. En algunas áreas el estrato arbustivo puede estar presente con elementos de Acacia cornigera (L.) Willd., Randia obcordata, Cassia occidentalis L., Calliandra grandiflora (L'Hér) Benth., Xylosma flexuosa y Curatella americana L. En otras ocasiones un pastizal es el dominante. El estrato herbáceo es comúnmente compuesto por Panicum trichidiachne Döll, Centrosema virginianum (L.) Benth., Malvastrum americanum (L.) Torr., Paspalum fasciculatum Willd. ex Flüggé, Setaria parviflora (Poir.) Kerguélen y Amaranthus spinosus L.

El pastizal es una comunidad resultado de la perturbación antropogénica al eliminar los elementos arbóreos y arbustivos de la vegetación original para actividades ganaderas, llamándolos potreros. Actualmente cubre una superficie de cerca de 36,159 ha, lo cual representa $28.2 \%$ del área. Se encuentra principalmente en la parte norte del municipio sobre pequeñas pendientes y partes bajas. En el estrato arbóreo permanecen algunos árboles aislados y dispersos, los cuales son relictos de la vegetación original, que fueron dejados para proporcionar sombra al ganado o como cercas vivas, encontrándose también especies introducidas. Algunos de los más frecuentes son Enterolobium cyclocarpum, Casuarina equisetifolia L., Manilkara zapota, Leucaena pulverulenta (Schltdl.) Benth., Bravaisia integerrima, Terminalia catappa L. y Parkinsonia aculeata L. En el estrato arbustivo son comunes Acacia farnesiana (L.) Willd., Nopalea dejecta (Salm-Dyck) Salm-Dyck, Zanthoxylum fagara (L.) Sarg. En el estrato herbáceo, que es el dominante, es frecuente encontrar Axonopus compressus (Sw.) P. Beauv., Cynodon plectostachyus (K. Schum.) Pilg., Panicum maximum Jacq., Cyperus ochraceus Vahl, Capraria frutescens (Mill.) Britten, Mimosa pudica L. y Malvastrum coromandelianum (L.) Garke. 
La vegetación secundaria, llamada localmente milcahual, es consecuencia de la agricultura migratoria, puede encontrarse en diferentes etapas de sucesión, por lo que su composición y estructura difiere de acuerdo a su edad. Ocupa una superficie aproximada de 5125 ha y representa $4 \%$ del territorio. El estrato arbóreo es escaso, algunas de las especies frecuentes son Parmentiera aculeata (Kunth) Seem., Diphysa americana (Mill.) M. Sousa, Bravaisia integerrima, Annona muricata L., Ehretia anacua (Terán \& Berland.) I.M. Johnst., Eugenia acapulcensis Steud. y Achatocarpus nigricans Triana. En el estrato arbustivo se encuentra una diversidad de especies, donde es frecuente Pisonia aculeata, Randia armata, Solanum hirtum Vahl, Curatella americana, Muntingia calabura L., Calliandra grandiflora y Annona globiflora Schtdl. En el estrato herbáceo suelen estar presentes Heliotropium angiospermum Murray, Chromolaena odorata, Solanum americanum Mill., Crotalaria retusa L., Abutilon trisulcatum (Jacq.) Urb. y Petiveria alliacea L.

Las comunidades de malezas arvenses están dominadas principalmente por plantas herbáceas que crecen en lugares perturbados. Álamo es un municipio con gran desarrollo en agricultura, sobresaliendo por la producción de cítricos y una extensa área cultivada (Aguilar, 2012) que es de aproximadamente 70,672 ha, 55.2\% del municipio. Algunos de los cultivos más importantes son naranja, mandarina, papaya, mango, plátano, chile, entre otros, por lo que el número de malezas es muy extenso, tanto las que se encuentran en los cultivos (arvenses), como las de orillas de caminos y poblados (ruderales). El estrato arbustivo está constituido por plantas semileñosas, que presentan una altura máxima de $2 \mathrm{~m}$. Algunas de las especies más abundantes son Cajanus cajan (L.) Huth, Ricinus communis, Abelmoschus esculentus (L.) Moench, Croton fruticulosus Engelm. ex Torr. y Muntingia calabura. En el estrato herbáceo las especies más frecuentes son Euphorbia heterophylla L., Amaranthus hybridus L., Erigeron bonariensis L., Parthenium hysterophorus L., Tridax procumbens L., Bidens pilosa L., Tithonia diversifolia (Hemsl.) A. Gray, Leonotis nepetifolia (L.) R. Br. y Malachra capitata (L.) L.

\section{DISCUSIÓN}

\section{Florística}

Los resultados aquí encontrados concuerdan con lo descrito por Castillo-Campos et al. (2011), quienes mencionan que las familias más diversas para el estado de Veracruz son las compuestas (Asteraceae), las leguminosas (Fabaceae), las gramíneas (Poaceae), las orquídeas (Orchidaceae) y las euforbiáceas (Euphorbiaceae). En general, coinciden con lo reportado para México por Rzedowski (1991) y Villaseñor (2003), destacando las primeras tres, que en conjunto concentran más de la cuarta parte de la flora de la zona de estudio. Fabaceae es la familia con mayor representación de especies, mientras que Asteraceae, de géneros. De acuerdo con Pennington et al. (2006), la riqueza de estos grupos es el patrón seguido en la región neotropical, encontrándose a las leguminosas como elementos frecuentes de las selvas (Trejo, 2010) y las compuestas como plantas indicadoras de áreas perturbadas (Pruski y Sancho, 2004). Por otro lado, familias que en regiones tropicales están bien representadas (Pennington et al., 2006; Trejo, 2010), en este estudio Malvaceae ocupa el cuarto lugar y Euphorbiaceae el quinto. De las 8400 especies estimadas para el estado de Veracruz por Gómez-Pompa et al. (2010), las 753 registradas en el municipio Álamo Temapache representan 8.95\%, mientras que sería $2.83 \%$ de las 26,495 estimadas para México (CONABIO, 2014). Si se compara con otros estudios florísticos locales, encontramos que la riqueza específica se mantiene alta, como el de Gutiérrez-Báez (1993) para el norte de Veracruz que abarca los municipios de Pánuco, Pueblo Viejo y Tampico Alto, reporta 577 especies $(6.8 \%$ de la flora estatal); el de Vázquez-Torres et al. (2010), para el Área Natural Protegida de la Sierra de Otontepec 350 especies ( $4.1 \%$ para el estado), y el de Palacios-Wassenaar et al. (2014), para la selva mediana subcaducifolia del centro del estado 230 ( $2.7 \%$ de la flora en Veracruz), con porcentajes más bajos de composición florística.

La zona presenta impactos graves por perturbación antrópica; a pesar de esto, conserva sitios muy reducidos en extensión con las comunidades naturales del área, de acuerdo con lo reportado para Veracruz por Gómez-Pom- 
pa (1977). Consideramos que de la superficie total del municipio, que es de 127,937.62 ha, un poco más de la mitad está ocupada por el área agrícola. Cerca de una cuarta parte es pastizal inducido y otra extensión importante es de vegetación secundaria o acahual, usualmente asociado con áreas agrícolas que han sido abandonadas. Estas dos comunidades, propiciadas por actividades humanas, sumadas a las áreas urbanas, ocupan una proporción muy alta de área municipal, quedando menos de $10 \%$ con vegetación natural. El bosque tropical subcaducifolio, en la actualidad, se encuentra bien conservado para el centro del estado de acuerdo con lo reportado por Palacios-
Wassenaar et al. (2014). Sin embargo, el bosque tropical perennifolio ocupa una superficie muy reducida, está muy deteriorado y se localiza en áreas poco accesibles de algunos cerros. La vegetación acuática y subacuática tienen los valores más bajos, restringidas a corrientes y cuerpos de agua (Cuadro 3, Fig. 2). Aunado a estos valores bajos de lo que queda de vegetación natural, se estima que el bosque tropical subcaducifolio será fuertemente afectado en un futuro y prácticamente eliminado dentro de unos 35 años por efectos del cambio climático (Estrada et al., 2015). Una situación similar ha sido reportada para esta comunidad en Michoacán por Rzedowski et al. (2014).
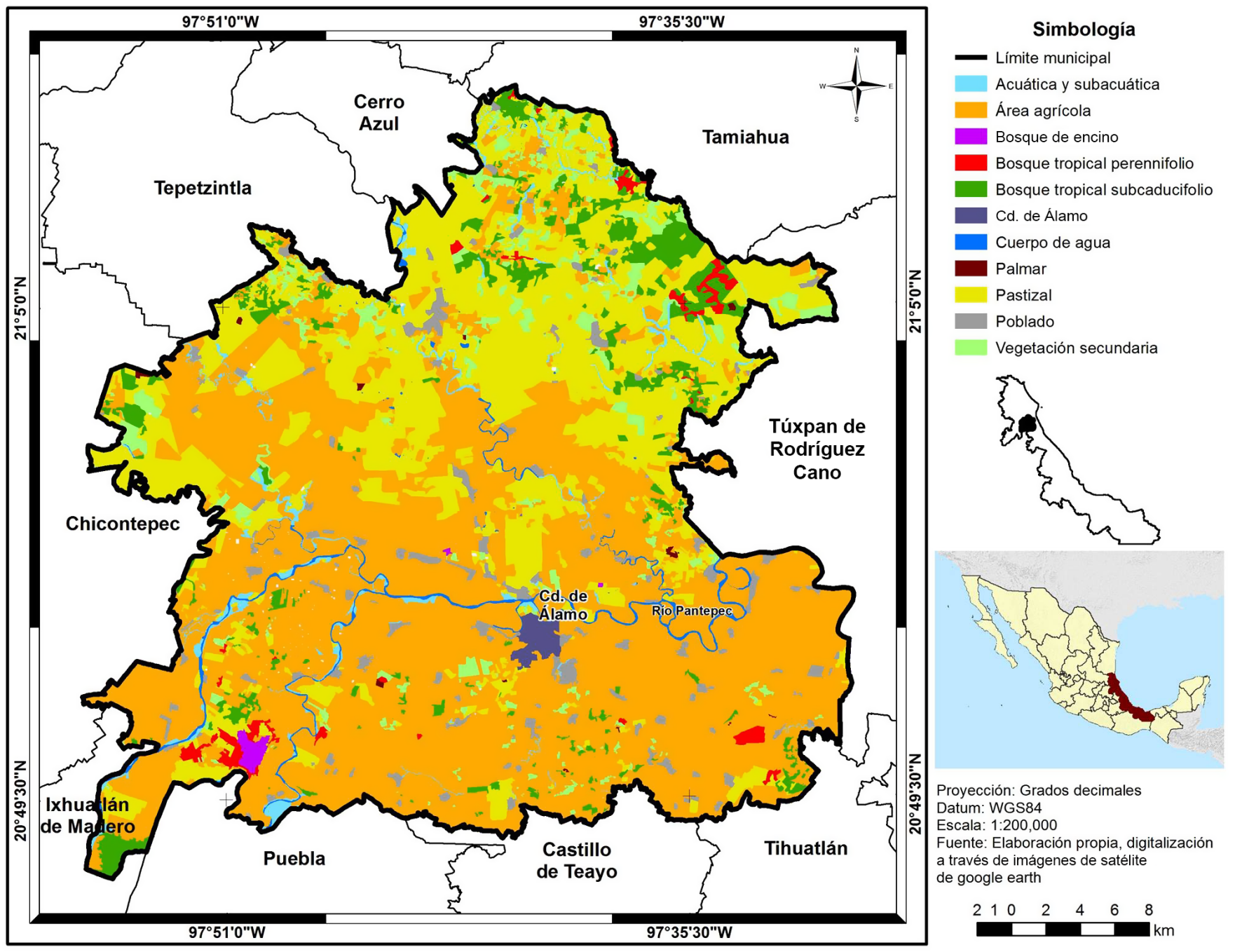

Figura 2: Mapa de vegetación del municipio Álamo Temapache, Veracruz. 
Cuadro 3: Superficie calculada para los tipos de vegetación y uso del suelo del municipio Álamo Temapache, Veracruz.

\begin{tabular}{lcc}
\hline Vegetación y uso del suelo & Superficie (ha) & Porcentaje (\%) \\
\hline Área agrícola y comunidad & $70,672.172$ & 55.3 \\
de malezas arvenses & 264.486 & 0.20 \\
Bosque de encino & 1302.353 & 1.01 \\
Bosque tropical perennifolio & 6333.218 & 4.95 \\
Bosque tropical subcaducifolio & 568.708 & 0.44 \\
Cd. de Álamo & 1430.694 & 1.14 \\
Cuerpos de agua & 96.665 & 0.07 \\
Infraestructura & 334.110 & 0.27 \\
Palmar & $36,159.803$ & 28.2 \\
Pastizal & 3648.970 & 2.84 \\
Poblados & & \\
Vegetación acuática y & $\mathbf{2 0 0 1 . 2 9 7}$ & 1.57 \\
Subacuática & 5125.138 & 4.01 \\
Vegetación secundaria & $\mathbf{1 2 8 , 0 3 7 . 6 2 0}$ & $\mathbf{1 0 0}$ \\
\hline Total & & \\
\hline
\end{tabular}

Como conclusión se puede mencionar que el municipio Álamo Temapache, ubicado en el norte del estado de Veracruz ha tenido una fuerte transformación en sus comunidades vegetales por el uso agrícola, ganadero y urbano, quedando solo áreas reducidas de vegetación natural. El área no había sido debidamente explorada desde el punto de vista florístico, lo que motivó el iniciar un inventario florístico y de vegetación.

\section{CONTRIBUCIONES DE AUTORES}

AFC, JAV y AEE diseñaron el estudio y escribieron el protocolo. JAV, AFC, AEE y DJC contribuyeron a la adquisición de datos y la interpretación y la escritura del manuscrito. Todos los autores contribuyeron a la discusión, revisión y aprobación del manuscrito final.

\section{FINANCIAMIENTO}

Este estudio fue apoyado por la Universidad Autónoma Agraria Antonio Narro, proyecto 40012100/Plantas endémicas y raras de Coahuila.

\section{AgradeCIMIENTOS}

A los revisores anónimos por su ayuda a la mejora de la presentación del escrito.

\section{LITERATURA CITADA}

Aguilar, C. E. 2012. Estructura de poder, petróleo y problemática ambiental en Álamo, Veracruz (1913-1938). Tesis de maestría en Historia. Colegio de San Luis, A.C. San Luis Potosí, México. 271 pp.

APG. 2016. Angiosperm Phylogeny Group. An update of the angiosperm phylogeny group classification for the orders and families of flowering plants: APG IV. Botanical Journal of the Linnean Society 18(1): 1-20. DOI: http:// dx.doi.org/10.1111/boj.12385

Basáñez, A. J., J. L. Alanis y E. Badillo. 2008. Composición florística y estructura arbórea de la selva mediana subperennifolia del ejido El Remolino, Papantla, Veracruz. Avances en Investigación Agropecuaria 12(2): 3-21.

Benítez, G., M. T. Pulido-Salas y M. Equihua-Zamora. 2004. Árboles multiusos nativos de Veracruz para reforestación restauración y plantaciones. Comisión Nacional Forestal, Sistema de Investigación del Golfo de México e Instituto de Ecología, A.C. Xalapa, México. 288 pp.

Castillo-Campos, G., J. Robles-González y M. E. MedinaAbreo. 2003. Flora y Vegetación de la Sierra Cruz Tetela, Veracruz, México. Polibotánica 15: 41-87.

Castillo-Campos, G., S. Avendaño-Reyes y M. E. MedinaAbreo. 2011. Flora y vegetación. In: Cruz-Angón, A. (ed.). La biodiversidad en Veracruz, estudio de estado. Comisión Nacional para el Conocimiento y Uso de la Biodiversidad. México, D.F., México. Pp. 163-180.

CONABIO. 2014. Biodiversidad Mexicana. Comisión Nacional para el Conocimiento y Uso de la Biodiversidad (en línea). La Gran Familia. Plantas. http://www.biodiversidad. gob.mx/especies/gran_familia/planta.html (consultado noviembre de 2014).

Cruz-Elizalde, R. y A. Ramírez-Bautista. 2012. Diversidad de reptiles en tres tipos de vegetación del estado de Hidalgo, México. Revista Mexicana de Biodiversidad 83(2): 458467. 
Daniel, T. F. 1992. Acanthaceae. Mendoncioideae of Mexico. Acta Botanica Mexicana 17: 53-60. DOI: http://dx.doi. org/10.21829/abm17.1992.636

Estrada-Contreras, I., M. Equihua, G. Castillo-Campos y O. Rojas-Soto. 2015. Climate change and effects on vegetation in Veracruz, Mexico: an approach using ecological niche modelling. Acta Botanica Mexicana 112: 73-93. DOI: http://dx.doi.org/10.21829/abm112.2015.1090

Flores-Villela, O. y P. Gerez-Fernández. 1994. Biodiversidad y conservación en México: Vertebrados, vegetación y uso del suelo. Comisión Nacional para el Conocimiento y uso de la Biodiversidad. 2a ed. México, D.F., México. 439 pp.

Fryxell, P. A. 1998. A synopsis of the neotropical species of Triumfetta (Tiliaceae). In: Mathew, P. y M. Sivadasan (eds.). Diversity and taxonomy of tropical flowering plants. Mentor Books. Calicut, India. Pp. 167-192.

García, E. 1998. Modificaciones al sistema de clasificación climática de Köppen, para adaptarlo a las condiciones de la República Mexicana. $5^{\text {a }}$ ed. Instituto de Geografía, Universidad Nacional Autónoma de México. México, D.F., México. 90 pp.

Gómez-Pompa, A. 1977. Ecología de la vegetación del estado de Veracruz. Editorial Continental. México, D.F., México. $91 \mathrm{pp}$.

Gómez-Pompa, A., T. Krömer y R. Castro-Cortés. 2010. Atlas de la Flora de Veracruz: un patrimonio natural en peligro. Comisión del estado de Veracruz para la conmemoración de la Independencia Nacional y La Revolución Mexicana. Xalapa, México. 528 pp.

Gutiérrez-Báez, C. 1993. Lista Florística del Norte del Estado de Veracruz. (Pánuco, Pueblo Viejo y Tampico Alto). La Ciencia y el Hombre 15: 71-99.

INEGI. 2009. Guía para la interpretación de cartografía uso del suelo y vegetación. Escala 1: 250000 Serie III. Instituto Nacional de Estadística y Geografía. México, D.F., México.

INEGI. 2013. Cartografía uso del suelo y vegetación. Escala 1: 50,000 Serie V. 2a ed. Instituto Nacional de Estadística y Geografía. México, D.F., México.

INEGI. 2014. Anuario Estadístico del estado de Veracruz. Instituto Nacional de Estadística y Geografía. Xalapa, México.
Juárez-Jaimes, V., L. O. Alvarado-Cárdenas y J. L. VillaseñorRíos. 2007. La familia Apocynaceae sensu lato en México: diversidad y distribución. Revista Mexicana de Biodiversidad 78: 459-482.

Martínez, E. y F. Ojeda. 1977. Vegetación del sureste de Tamaulipas, México. Biótica 2(2): 1-45.

Martínez, E. y C. H. Ramos. 2012. Bignoniaceae. Flora del Valle de Tehuacán-Cuicatlán 104: 1-58.

Moreno, C. E. 2001. Métodos para medir la biodiversidad. M\&T-Manuales y Tesis. Sociedad Entomológica Aragonesa. Zaragoza, España. 81 pp.

Palacios-Wassenaar, O., G. Castillo-Campos, S. M. VázquezTorres y S. del Amo-Rodríguez. 2014. Flora vascular de la selva mediana subcaducifolia del centro de Veracruz, México. Revista Mexicana de Biodiversidad 85: 125-142. DOI: http://dx.doi.org/10.7550/rmb.34663

Pennington, R. T., G. P. Lewis y J. A. Ratter. 2006. An overview of the plant diversity, biogeography and conservation of neotropical savannas and seasonally dry forest. In: Pennington, R. T., G. P. Lewis y J. A. Ratter (eds.). Neotropical savannas and seasonally dry forest: Plant diversity, biogeography and conservation. The Systematics Association, CRC Press, Taylor and Francis Group. Boca Raton, USA. Pp. 1-25. DOI: http://dx.doi. org/10.1201/9781420004496.ch1

Pruski, J. F. y G. Sancho. 2004. Asteraceae. In: Smith, N., S. A. Mori, A. Henderson, D. W. Stevenson y S. V. Heald (eds.). Flowering Plants of the Neotropics. Princeton University Press. Princeton, USA. Pp. 33-39.

Puig, H. 1974. Phytogeographie et ecologie de la Huasteca (NE du Mexique). Tesis de doctorado. Université Paul Sabatier. Toulouse, France. 547 pp.

QGIS Development Team. 2014. Quantum GIS Geographic Information System Version 2.6.0-Brighton. Disponible en: http://qgis.osgeo.org (consultado noviembre de 2015).

Riba, R. 1993. Mexican pteridophytes: Distribution and endemism. In: Ramamoorthy, T. P., R. Bye, A. Lot, y J. $\mathrm{Fa}$ (eds.). Biological diversity of Mexico: origins and distribution. Oxford University Press. Nueva York, USA. Pp. 379-395. 
Rosas-Sánchez, A. R. 2011. Selección del sitio, anteproyecto y operación del relleno sanitario de Tuxpan, Ver. Reporte técnico. Universidad Veracruzana. Xalapa, México. 110 pp.

Rzedowski, J. 1978. La vegetación de México. Limusa. México, D.F., México. 432 pp.

Rzedowski，J. 1991. Diversidad y orígenes de la flora fanerogámica de México. Acta Botanica Mexicana 14: 3-21. DOI: http://dx.doi.org/10.21829/abm14.1991.611

Rzedowski, J., S. Zamudio, G. Calderón de Rzedowski y A. Paizanni. 2014. El bosque tropical caducifolio en la cuenca lacustre de Pátzcuaro (Michoacán, México). Flora del Bajío y de regiones adyacentes. Fascículo complementario 29: 1-14.

Sánchez-González, A. y M. González-Ledezma. 2007. Técnicas de recolecta de plantas y herborización. In: ContrerasRamos, A., C. Cuevas-Cardona, I. Goyenechea y U. Iturbide (eds.). La sistemática, base del conocimiento de la biodiversidad. Universidad Autónoma del Estado de Hidalgo. Pachuca, México. Pp. 123-133.

SEFIPLAN. 2009. Sistema de Información Municipal Álamo Temapache, Veracruz. Secretaría de Finanzas y Planeación del Estado de Veracruz. Xalapa, México.

SEFIPLAN. 2014. Sistema de Información Municipal. Cuadernillos Municipales Álamo Temapache, Veracruz. Secretaría de Finanzas y Planeación del Estado de Veracruz. Xalapa, México.

SEMARNAT. 2010. NORMA Oficial Mexicana NOM-059-SEMARNAT-2010. Protección ambiental-Especies nativas de México de flora y fauna silvestres-Categorías de riesgo y especificaciones para su inclusión, exclusión o cambioLista de especies en riesgo. Secretaría del Medio Ambiente y Recursos Naturales. Diario Oficial de la Federación. Cd. Mx., México. http://dof.gob.mx/nota_detalle.php?co digo $=5173091 \&$ fecha $=30 / 12 / 2010$.

Sousa, M. y A. Delgado. 1998. Leguminosas mexicanas: fitogeografía, endemismo y orígenes. In: Ramamoorthy, T. P., R. Bye, A. Lot y J. Fa (eds.). Diversidad Biológica de México: orígenes y distribución. Universidad Nacional Autónoma de México. México, D.F., México. Pp. 449-500.
Steinmann, V. W. 2002. Diversidad y endemismo de la familia Euphorbiaceae en México. Acta Botanica Mexicana 61: 61-93. DOI: http://dx.doi.org/10.21829/abm61.202.909

Trejo, I. 2010. Las selvas secas del Pacífico Mexicano. In: Cevallos, G., L. Martínez, A. García, E. Espinoza, J. Bezaury y R. Dirzo (eds.). Diversidad, amenazas y áreas prioritarias para la conservación de las selvas secas del Pacífico de México. Fondo de Cultura Económica, Comisión Nacional para el Conocimiento y Uso de la Biodiversidad. México, D.F., México. Pp. 41-51.

The Plant List. 2015. Version 1.1. http://www.theplantlist.org (consultado noviembre de 2015).

TROPICOS. 2015. Tropicos.org. at Missouri Botanical Garden. http://www.tropicos.org (consultado junio de 2013 a septiembre de 2015).

Vázquez-Torres, S. M., C. I. Carvajal-Hernández y A. M. Aquino-Zapata. 2010. Áreas naturales protegidas. Sierra de Otontepec. In: Benítez-Badillo, G. y C. Welsh- odríguez (eds.). Atlas del patrimonio cultural, histórico y cultural de Veracruz, Patrimonio natural. Comisión del Estado de Veracruz para la Conmemoración de la Independencia Nacional y de la Revolución Mexicana, Gobierno del Estado de Veracruz/Universidad Veracruzana. Xalapa, Veracruz. Pp. 265.

Villaseñor, J. L. 2003. Diversidad y distribución de las Magnoliophyta de México. Interciencia 28: 160-167.

Villaseñor, J. L. 2004. Los géneros de plantas vasculares de la flora de México. Boletín de la Sociedad Botánica de México 75: 105-135.

Villaseñor, J. L. y E. Ortiz. 2014. Biodiversidad de las plantas con flores en (División Magnoliophyta) México. Revista Mexicana de Biodiversidad 85: 134-142. DOI: http:// dx.doi.org/10.7550/rmb.31987

Willmann, D., E. Schmidt, M. Heunruch y R. Horst. 2000. Verbenaceae. Flora del Valle de Tehuacán-Cuicatlán 27: $1-75$. 
Apéndice. Lista florística del municipio Álamo Temapache, Veracruz. Grupo de colectores: Axel Francisco de la Cruz, Alberto Francisco Cruz, Senovio Francisco Cruz, Zeferino Francisco. Se presenta la lista florística en orden alfabético. Se indica por especie, el nombre común (cuando se conoce) (NC), número de colecta (CO), forma de vida (FV). Tipo de vegetación (TV): acuática y subacuática (ACS), malezas arvenses (ARV), bosque de encino (BE), bosque tropical perennifolio (BTP), bosque tropical subcaducifolio (BTS), palmar (PLM), pastizal (PTZ), vegetación secundaria (VSEC). Forma de vida: Arbórea (A), Arbustiva (Ar), Bejuco (B), Epífita (E), Herbácea (H) y Parásita (P). Todas las colectas fueron depositadas en el herbario ANSM.

\begin{tabular}{llllll}
\hline TAXA & CO & NC & FV & TV \\
\hline PTERIDOFITAS Y AFINES
\end{tabular}

Adiantaceae

Adiantum tenerum Sw.

Adiantum tricholepis Fée

Anemiaceae

Anemia adiantifolia (L.) Sw.

Davalliaceae

Nephrolepis exaltata (L.) Schott

Equisetaceae

Equisetum myriochaetum Schltdl. \& Cham.

Hymenophyllaceae

Trichomanes krausii Hook. \& Grev.

Marsileaceae

Marsilea macropoda Engelm. ex A. Braun

Polypodiaceae

Campyloneurum amphostenon (Kunze ex Klotzsch) Fée

Enterosora ecostata (Sodiro) L.E. Bishop

Microgramma nitida (J. Sm.) A.R. Sm.

Niphidium crassifolium (L.) Lellinger

Pteridaceae

Antrophyum ensiforme Hook.

Pellaea atropurpurea (L.) Link

Pellaea ovata (Desv.) Weath.

Pteris grandifolia L.

Pteris vittata L.

Vittaria lineata (L.) Sm.
$32,48,389$

476,521

14,639

244

helecho

alfombrilla

helecho

$\mathrm{H}$

1157

cola de caballo

$\mathrm{H}$

1054

472,1161

helecho trébol

$\mathrm{H}$
$1,421,422$

1201

14, 501, 637

376 helecho de tronco

E

E

E

$\mathrm{H}$

E

328, 671

320,333

508, 1289

338b, 110

325 alambrito

calahuala

alambrito

helecho grande

helecho

helecho de cabellera
E

BTP
BTP, BTS

ACS

ACS

BTP, BTS, PLM

BTP, BTS

BTP

BTP

BTP

BE, BTP, BTS

BTP
BTP

BE, BTP, BTS

BE, BTP, BTS

ACS, ARV, BTP, BTS

ACS, BTP, BTS

BE, BTP, BTS 
Acta Botanica Mexicana 121: 83-124 Octubre 2017

Apéndice. Continuación.

\begin{tabular}{lrrrr}
\hline TAXA & CO & NC & FV & TV \\
\hline Selaginellaceae & & & & \\
Selaginella delicatissima Linden ex A. Braun & 438,1242 & helecho de piedra & H & BE, BTP, BTS \\
Selaginella marginata (Humb. \& Bonpl. ex Willd.) Spring & $1264,1389 \mathrm{a}$ & helecho de piedra & H & BTP, BTS \\
Selaginella pallescens (C. Presl) Spring & $337,638,1479$ & selaginela & H & BE, BTP, BTS
\end{tabular}

Tectariaceae

Tectaria heracleifolia (Willd.) Underw.

31, 502, $628 \quad$ lengua de ciervo $\quad \mathrm{H}$

BE, BTP, BTS

\section{GIMNOSPERMAS}

Cupressaceae

Thuja occidentalis L.

ARV

Podocarpaceae

Podocarpus matudae Lundell

Zamiaceae

Dioon edule Lindl.

BE, BTS

\section{MAGNOLIDES}

Annonaceae

Annona globiflora Schltdl.

Annona muricata L.

$\begin{array}{rcc}484,670 & \text { anona de monte } & \mathrm{Ar} \\ 407,1388 & \text { guanábana } & \mathrm{A} \\ 423 & \text { anona } & \mathrm{A}\end{array}$

BTS, VSEC

Annona reticulata $\mathrm{L}$.

anona

A

ARV, BTS, VSEC

ARV, BTS

Aristolochiaceae

Aristolochia sp.

BTS

\section{Lauraceae}

Cassytha filiformis L.

Laurus nobilis L.

Licaria capitata (Cham. \& Schltdl.) Kosterm.

Persea americana Mill.

Persea schiedeana Nees

$\begin{array}{rcc}633 & \text { bejuco amarillo } & \text { B } \\ 33 & \text { laurel } & \text { A } \\ 1178 & \text { laurelillo } & \text { A } \\ 102 & \text { aguacate } & \text { A } \\ 1241 & \text { aguacate criollo } & \text { A }\end{array}$

B

A

A

A

A
VSEC

BE, BTP, BTS

BTP

ARV, BTS

BTP, BTS

Nymphaeaceae

Nelumbo lutea Willd.

806

nimpha

$\mathrm{H}$

ACS 
Apéndice. Continuación.

\begin{tabular}{lrrrr}
\hline TAXA & CO & NC & FV & TV \\
\hline Nymphaea alba L. & 1087 & nimpha & H & ACS \\
Nymphoides peltata (S.G. Gmel.) Kuntze & 807 & nimpha & H & ACS
\end{tabular}

Piperaceae

Peperomia blanda (Jacq.) Kunth

Piper amalago L.

Piper auritum Kunth

Piper hispidum Sw.

\section{MONOCOTILEDÓNEAS}

Alismataceae

Alisma subcordatum Raf.

Echinodorus berteroi (Spreng.) Fassett

Alstroemeriaceae

Bomarea edulis (Tussac) Herb.

Amaryllidaceae

Allium glandulosum Link \& Otto

Crinum erubescens Aiton

Hippeastrum sp.

Scadoxus multiflorus (Martyn) Raf.

Zephyranthes candida (Lindl.) Herb.

Zephyranthes macrosiphon Baker

Araceae

Caladium hortulanum Birdsey

Colocasia esculenta (L.) Schott

Dieffenbachia seguine (Jacq.) Schott

Lemna aequinoctialis Welw.

Monstera acuminata K. Koch

Monstera deliciosa Liebm.

Monstera lechleriana Schott

Pistia stratiotes L.

Spathiphyllum cochlearispathum (Liebm.) Engl.
824

752

631

834

920

1032

$$
\text { cebolla de monte }
$$

azucena

amarilis

cerillo

lirio de lluvia

lirio de lluvia
H

$\mathrm{H}$

$\mathrm{H}$

$\mathrm{H}$

$\mathrm{H}$

$\mathrm{H}$

450

823

913

1215

243, 460

248

636, 675

1081

716, 914

$\begin{array}{cc}\text { caladio } & \mathrm{H} \\ \text { malango } & \mathrm{Ar} \\ \text { amoena } & \mathrm{Ar} \\ \text { lenteja de agua } & \mathrm{H} \\ \text { bejuco de arpón } & \mathrm{E} \\ \text { costilla de Adán } & \mathrm{E} \\ \text { flor de San Marciano } & \mathrm{E} \\ \text { lechuga de agua } & \mathrm{H} \\ \text { cuna de Moisés } & \mathrm{E}\end{array}$

$\mathrm{H}$

Ar

$\mathrm{Ar}$

$\mathrm{H}$

E

E

E

$\mathrm{H}$

E
BTP

BE,VSEC

ARV, BTP, BTS

BTP, BTS 
Apéndice. Continuación.

\begin{tabular}{lrrrrr}
\hline TAXA & CO & NC & FV & TV \\
\hline Spathiphyllum ortgiesii Regel & 311 & cuna de Moisés & H & ARV \\
Syngonium neglectum Schott & 461,1205 & chapis & E & ACS, BE, BTP, BTS, PTZ \\
Syngonium podophyllum Schott & 65 & chapis & E & BTP, BTS \\
Syngonium sagittatum G.S. Bunting & 862,1166 & chapis & H & ACS, BE, BTP, BTS, PLM, PTZ, \\
& & & & VSEC
\end{tabular}

Arecaceae

Acrocomia mexicana Karw. ex Mart.

Astrocaryum mexicanum Liebm. ex Mart.

Attalea rostrata Oerst.

Chamaedorea elegans Mart.

Chamaedorea ernesti-augusti $\mathrm{H}$. Wendl.

Chamaedorea oblongata Mart.

Chamaedorea oreophila Mart.

Chamaedorea tepejilote Liebm.

Cocos nucifera $\mathrm{L}$.

Roystonea dunlapiana P.H. Allen

Sabal mexicana Mart.

$\begin{array}{rccc}423 & \text { coyol } & \text { A } & \text { BTS, PLM } \\ 236,861 & \text { palma cola de sirena } & \mathrm{Ar} & \text { BE, BTP, BTS } \\ 300 & \text { coyol real } & \mathrm{A} & \text { BTS, PLM } \\ 948 & \text { palma fina } & \mathrm{H} & \text { BE, BTP, BTS } \\ 958 & \text { palmilla cola de sirena } & \mathrm{Ar} & \text { BE, BTP, BTS } \\ 1091 & \text { palmilla de hoja ancha } & \mathrm{Ar} & \text { BTP, BTS } \\ 314 & \text { palmilla } & \mathrm{Ar} & \text { BTP, BTS } \\ 466,931 & \text { palmilla } & \mathrm{Ar} & \text { BTP, BTS } \\ 1198 & \text { palma cocotera } & \mathrm{A} & \text { ACS, ARV } \\ 1197 & \text { palmera } & \mathrm{A} & \text { ARV, PTZ } \\ 1248 & \text { palma mexicana } & \mathrm{A} & \text { BTS, PLM }\end{array}$

\section{Asparagaceae}

Agave americana $\mathrm{L}$.

Agave fourcroydes Lem.

Asparagus setaceus (Kunth) Jessop

Cordyline fruticosa (L.) A. Chev.

Cordyline rubra Otto \& A. Dietr.

Echeandia flavescens (Schult. \& Schult. f.) Cruden

Echeandia mexicana Cruden

Manfreda variegata (Jacobi) Rose

Sansevieria hyacinthoides (L.) Druce

Yucca gigantea Lem.

$\begin{array}{rccc}964 & \text { maguey cenizo } & \text { Ar } & \text { ARV } \\ 415 & \text { maguey } & \text { Ar } & \text { ARV } \\ 321 & \text { helecho plumoso } & \text { B } & \text { ARV, VSEC } \\ 420 & \text { cordelia } & \text { Ar } & \text { ARV } \\ 840 & \text { dracena } & \text { Ar } & \text { ARV, BTP } \\ 53,607 & \text { cebollita flor amarilla } & \text { H } & \text { ARV, PLM, PTZ } \\ 467,1034 & \text { tule } & \text { H } & \text { BE, BTP, PTZ } \\ 433 & & \text { Ar } & \text { ARV, BE, BTS } \\ 212 & \text { espada } & \text { H } & \text { ARV } \\ 264 & \text { izote } & \text { A } & \text { BE, BTP, BTS }\end{array}$

Bromeliaceae

Aechmea bracteata (Sw.) Griseb.

335 bromelia E

Bromelia karatas L.

BE, BTP, BTS

BE, BTP

BE, BTS

BE, BTP, BTS, PTZ 
Apéndice. Continuación.

\begin{tabular}{|c|c|c|c|c|}
\hline TAXA & $\mathrm{CO}$ & $\mathrm{NC}$ & FV & TV \\
\hline Tillandsia ionantha Planch. & 796 & gallito & $\mathrm{E}$ & BE, BTP, BTS \\
\hline Tillandsia juncea (Ruiz \& Pav.) Poir. & 260 & gallito & $\mathrm{E}$ & BE, BTP, BTS \\
\hline Tillandsia limbata Schltdl. & 676,1042 & gallito & $\mathrm{E}$ & BE, BTP, BTS \\
\hline Tillandsia polystachia (L.) L. & 296 & gallito & $\mathrm{E}$ & BTP, BTS \\
\hline Tillandsia schiedeana Steud. & 468,649 & gallito & $\mathrm{E}$ & BE, BTP, BTS \\
\hline Tillandsia usneoides (L.) L. & 247,859 & heno & $\mathrm{E}$ & BE, BTP, BTS \\
\hline Tillandsia utriculata $\mathrm{L}$. & 1000 & gallito & $\mathrm{E}$ & BE, BTP, BTS \\
\hline Tillandsia viridiflora (Beer) Baker & 1043 & gallito & $\mathrm{E}$ & BE, BTP, BTS \\
\hline \multicolumn{5}{|l|}{ Cannaceae } \\
\hline Canna glauca $\mathrm{L}$. & 873 & canna & $\mathrm{Ar}$ & $\mathrm{ACS}$ \\
\hline Canna indica $\mathrm{L}$. & 360,851 & canna & $\mathrm{Ar}$ & ACS \\
\hline \multicolumn{5}{|l|}{ Commelinaceae } \\
\hline Callisia sp. & 1156 & hierba del pollo & $\mathrm{H}$ & ACS, BE, BTP \\
\hline Commelina benghalensis $\mathrm{L}$. & 377 & hierba del pollo & $\mathrm{H}$ & ACS, BE, BTP, BTS \\
\hline Commelina diffusa Burm. f. & 409,852 & hierba del pollo & $\mathrm{H}$ & BE, BTP, BTS \\
\hline Commelina erecta $\mathrm{L}$. & 474,1250 & hierba del pollo & $\mathrm{H}$ & ACS, BE, BTP, BTS \\
\hline Gibasis geniculata (Jacq.) Rohweder & 1155 & & $\mathrm{H}$ & BTP, BTS \\
\hline Tradescantia pallida (Rose) D.R. Hunt & 439 & & $\mathrm{H}$ & ВТP \\
\hline Tradescantia spathacea Sw. & 609,754 & cola de pollo & $\mathrm{H}$ & ACS, BE, BTP, BTS, VSEC \\
\hline Tradescantia zebrina Heynh. ex Bosse & 73 & cola de pollo & $\mathrm{H}$ & ACS, ARV, BTP, BTS \\
\hline \multicolumn{5}{|l|}{ Costaceae } \\
\hline Costus pulverulentus C. Presl & 854 & caña agria & $\mathrm{Ar}$ & ACS \\
\hline \multicolumn{5}{|l|}{ Cyperaceae } \\
\hline Cyperus alternifolius $\mathrm{L}$. & 790 & tule papiro & $\mathrm{H}$ & ACS, BE, BTS, VSEC \\
\hline Cyperus digitatus Roxb. & 221,850 & tule & $\mathrm{H}$ & BE, BTP, BTS \\
\hline Cyperus esculentus L. & 545,816 & tule & $\mathrm{H}$ & ACS, ARV, BTS, VSEC \\
\hline Cyperus ferax Rich. & 745 & tule & $\mathrm{H}$ & $\mathrm{BE}$ \\
\hline Cyperus humilis Kunth & 611 & tule & $\mathrm{H}$ & ACS, ARV \\
\hline Cyperus iria $\mathrm{L}$. & 610,1210 & tule & $\mathrm{H}$ & ACS, BE, BTS, PLM, PTZ, VSEC \\
\hline Cyperus macrocephalus Liebm. & 692,938 & tule & $\mathrm{H}$ & ACS, ARV, BTS, BTP, PLM, PTZ \\
\hline Cyperus ochraceus Vahl & 475,691 & tule & $\mathrm{H}$ & ACS, ARV, PLM, PTZ, VSEC \\
\hline
\end{tabular}


Apéndice. Continuación.

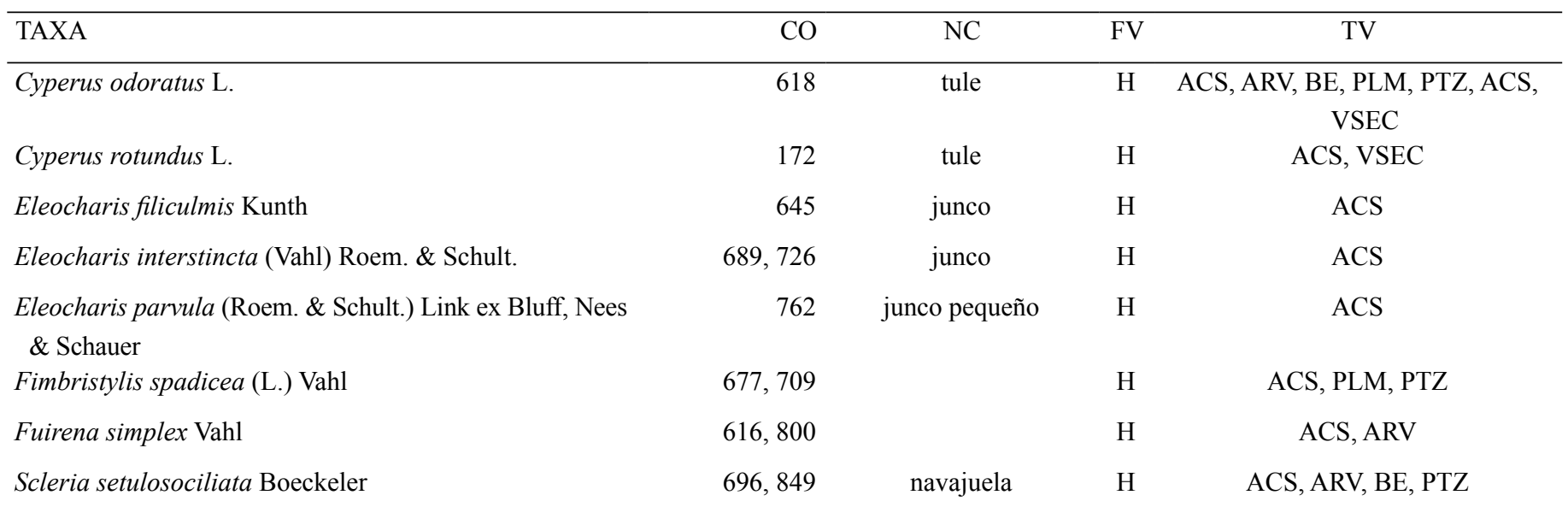

Dioscoreaceae

Dioscorea alata L.

13

Dioscorea convolvulacea Schltdl. \& Cham.

Dioscorea mexicana Scheidw.

Heliconiaceae

Heliconia latispatha Benth.

Heliconia pendula Wawra

Heliconia rostrata Ruiz \& Pav.

Heliconia schiedeana Klotzsch

Marantaceae

Maranta arundinacea $\mathrm{L}$.

Maranta gibba Sm.

Thalia geniculata $\mathrm{L}$.

Musaceae

Musa ornata Roxb.

Musa paradisiaca $\mathrm{L}$.

Orchidaceae

Catasetum integerrimum Hook.

Cohniella ascendens (Lindl.) Christenson

Epidendrum stamfordianum Bateman

Myrmecophila tibicinis (Bateman) Rolfe
234

876

795

751

652

$244,548,678$

1115

986

612

481

843

1048

617,1241 maranta

papatilla

popal

plátano

plátano

$\mathrm{Ar}$

Ar

ARV

ARV

ACS
BTP, BTS

ACS, BE, BTP, BTS

BE, BTP, BTS

ACS, BTP

ACS, ARV, BE, BTP, BTS

BTP

ACS, BTP, BTS 
Apéndice. Continuación.

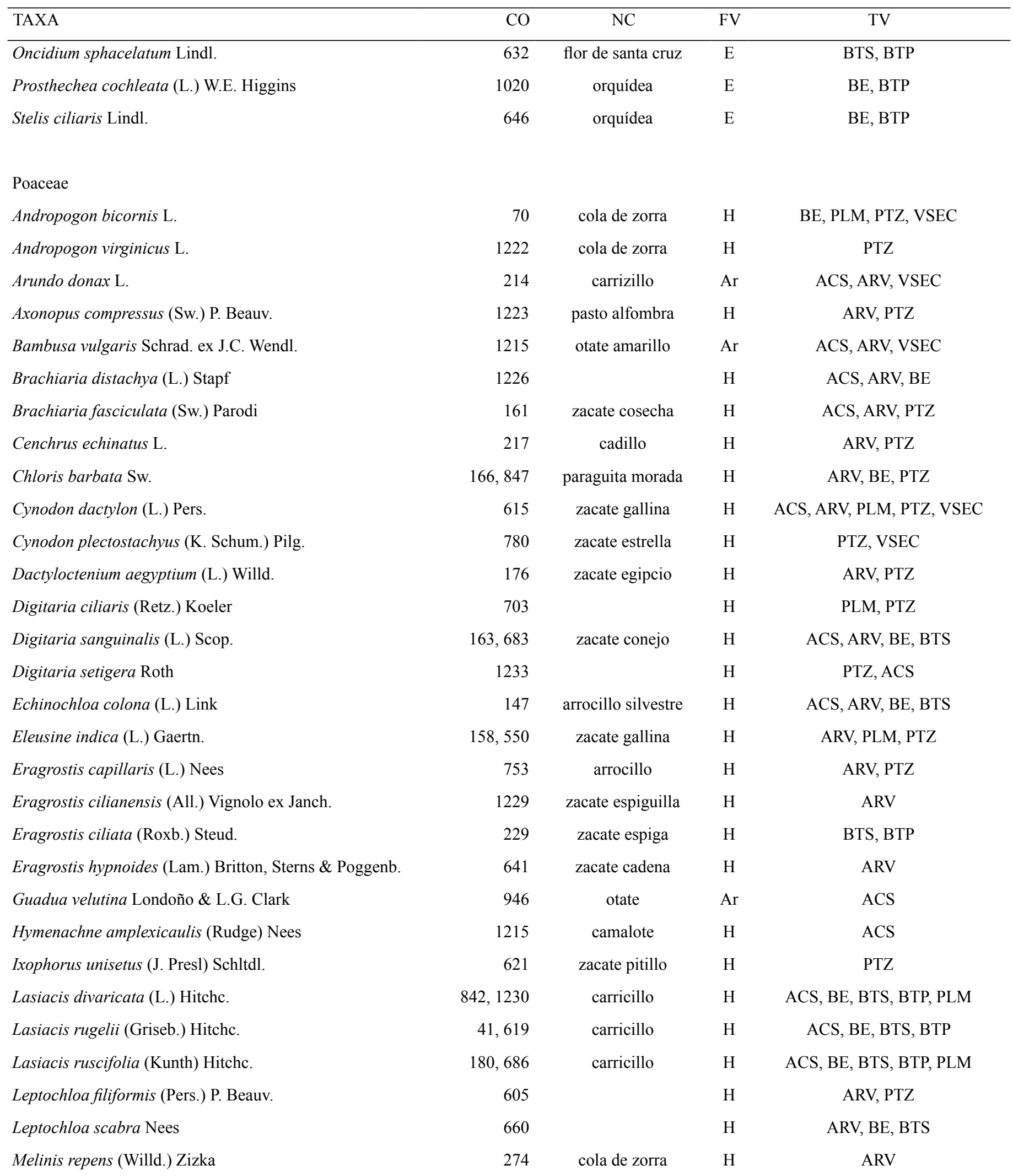


Apéndice. Continuación.

\begin{tabular}{|c|c|c|c|c|}
\hline TAXA & $\mathrm{CO}$ & $\mathrm{NC}$ & FV & TV \\
\hline Panicum acuminatum $\mathrm{Sw}$. & 1232 & zacate cosecha & $\mathrm{H}$ & ACS, ARV \\
\hline Panicum dichotomiflorum Michx. & 1199 & & $\mathrm{H}$ & PTZ \\
\hline Panicum maximum Jacq. & 140 & zacate guinea & $\mathrm{H}$ & PTZ, VSEC \\
\hline Panicum trichidiachne Döll. & 1068 & & $\mathrm{H}$ & ARV, PTZ \\
\hline Paspalum conjugatum P.J. Bergius & 620,983 & & $\mathrm{H}$ & ACS, BE, VSEC \\
\hline Paspalum distichum $\mathrm{L}$. & 63,485 & & $\mathrm{H}$ & ACS, PTZ \\
\hline Paspalum fasciculatum Willd. ex Flüggé & 1234 & & $\mathrm{H}$ & ACS, ARV, VSEC \\
\hline Paspalum virgatum $\mathrm{L}$. & 1087 & & $\mathrm{H}$ & ARV, PTZ, VSEC \\
\hline Pennisetum purpureum Schumach. & 715,1222 & zacate pluma & $\mathrm{H}$ & ACS, ARV \\
\hline Pennisetum setaceum (Forssk.) Chiov. & 1242 & zacate gusano & $\mathrm{H}$ & ARV, PTZ \\
\hline Saccharum officinarum $\mathrm{L}$. & 680 & caña & $\mathrm{Ar}$ & ARV \\
\hline Setaria parviflora (Poir.) Kerguélen & 553,1252 & pasto gusano & $\mathrm{H}$ & ARV, PLM, PTZ, VSEC \\
\hline Setaria verticillata (L.) P. Beauv. & 647 & & $\mathrm{H}$ & ACS, ARV, PLM, PTZ \\
\hline Sorghum halepense (L.) Pers. & 144 & zacate johnson & $\mathrm{H}$ & ARV, PLM, PTZ, VSEC \\
\hline Sporobolus indicus (L.) R. Br. & 665,841 & pasto alambre & $\mathrm{H}$ & ARV, PTZ, VSEC \\
\hline
\end{tabular}

Pontederiaceae

Eichhornia crassipes (Mart.) Solms

Heteranthera limosa (Sw.) Willd.

724 lirio acuático $\mathrm{H}$

ACS

1153 lila de agua $\mathrm{H}$

ACS, ARV

Pontederia sagittata C. Presl

1202

$\mathrm{H}$

ACS

Potamogetonaceae

Potamogeton foliosus Raf.

ACS

Smilacaceae

Smilax aristolochiifolia Mill.

$\begin{array}{rccc}220,555 & \text { zarcilla } & \text { B } & \text { ACS, BTS, VSEC } \\ 1042 & \text { zarcilla } & \text { B } & \text { ACS, BTS, VSEC } \\ 483,996 & \text { zarcilla espinosa } & \text { B } & \text { ACS, BTS, VSEC }\end{array}$

Smilax glauca Walter

483,996

zarcilla espinosa

ACS, BTS, VSEC 
Apéndice. Continuación.

\begin{tabular}{|c|c|c|c|c|}
\hline TAXA & $\mathrm{CO}$ & $\mathrm{NC}$ & FV & TV \\
\hline \multicolumn{5}{|l|}{ Typhaceae } \\
\hline Typha domingensis Pers. & 599 & tule & $\mathrm{H}$ & $\mathrm{ACS}$ \\
\hline \multicolumn{5}{|l|}{ Zingiberaceae } \\
\hline Alpinia purpurata (Vieill.) K. Schum. & 408 & platanillo & $\mathrm{Ar}$ & ARV, ACS \\
\hline \multicolumn{5}{|l|}{ EUDICOTILEDÓNEAS } \\
\hline \multicolumn{5}{|l|}{ Acanthaceae } \\
\hline Blechum pyramidatum (Lam.) Urb. & 184,887 & cancerillo & $\mathrm{H}$ & ARV, BE, PLM, PTZ, VSEC \\
\hline Bravaisia integerrima (Spreng.) Standl. & $38,953,1299$ & & A & BTS, PTZ, VSEC \\
\hline Dicliptera brachiata Spreng. & $542,989,1482$ & & $\mathrm{H}$ & ARV, PTZ, PLM, VSEC \\
\hline Dicliptera sexangularis (L.) Juss. & 712,987 & nimis & $\mathrm{H}$ & ARV, PTZ \\
\hline Elytraria bromoides Oerst. & 800 & & $\mathrm{H}$ & ARV \\
\hline Elytraria imbricata (Vahl) Pers. & 1240 & cordoncillo & $\mathrm{H}$ & ARV, PTZ, PLM, VSEC \\
\hline Justicia brandegeeana Wassh. \& L.B. Sm. & 129,925 & cola de camarón & $\mathrm{Ar}$ & BE, BTS \\
\hline Megaskepasma erythrochlamys Lindau & 410 & pavoncillo rojo & $\mathrm{Ar}$ & ARV \\
\hline Odontonema callistachyum (Schltdl. \& Cham.) Kuntze & 667,1246 & canutillo & $\mathrm{Ar}$ & BTP, BTS \\
\hline Odontonemanitidum (Jacq.) Kuntze & 992 & & $\mathrm{Ar}$ & BTS \\
\hline Ruellia inundata Kunth & 226 & hierba del toro & $\mathrm{H}$ & ARV, BTS, PTZ, VSEC \\
\hline Ruellia lactea Cav. & 184,669 & maravilla de monte & $\mathrm{H}$ & ACS, ARV, PTZ, VSEC \\
\hline Ruellia nudiflora (Engelm. \& A. Gray) Urb. & $68,539,1285$ & maravilla de monte & $\mathrm{H}$ & ACS, ARV, BTS, PTZ, VSEC \\
\hline Thunbergia alata Bojer ex Sims & 62 & ojo de pájaro & $\mathrm{B}$ & VSEC \\
\hline \multicolumn{5}{|l|}{ Achatocarpaceae } \\
\hline Achatocarpus nigricans Triana & 993,1089 & espino blanco & A & BE, BTS, PLM, PTZ \\
\hline \multicolumn{5}{|l|}{ Actinidiaceae } \\
\hline Saurauia cana B.T. Keller \& Breedlove & 1029 & pipicho & $\mathrm{Ar}$ & BTS \\
\hline Saurauia yasicae Loes. & 245,1167 & palo colorado & A & BTS, BTP \\
\hline \multicolumn{5}{|l|}{ Adoxaceae } \\
\hline Sambucus canadensis L. & 881,1107 & sauco & $\mathrm{Ar}$ & ARV, VSEC \\
\hline Viburnum ciliatum Greenm. & 44,552 & platanillo & $\mathrm{Ar}$ & BE, PLM, VSEC \\
\hline Viburnum hartwegii Benth. & 381,1477 & chilpatillo & $\mathrm{Ar}$ & PLM, PTZ, VSEC \\
\hline
\end{tabular}


Apéndice. Continuación.

\begin{tabular}{|c|c|c|c|c|}
\hline TAXA & $\mathrm{CO}$ & $\mathrm{NC}$ & FV & TV \\
\hline \multicolumn{5}{|l|}{ Amaranthaceae } \\
\hline Achyranthes aspera L. & 546,882 & cola de tejón & $\mathrm{H}$ & ARV, PLM, PTZ, VSEC \\
\hline Amaranthus cruentus L. & 23,525 & quelite rojo & $\mathrm{H}$ & ARV, PLM, PTZ, VSEC \\
\hline Amaranthus hybridus L. & 143,1011 & quelite & $\mathrm{H}$ & ARV, BE, PLM, PTZ, VSEC \\
\hline Amaranthus spinosus $\mathrm{L}$. & 157,447 & quelite de puerco & $\mathrm{H}$ & ARV, PLM, VSEC \\
\hline Celosia argentea $\mathrm{L}$. & 734 & mano de león & $\mathrm{H}$ & ARV \\
\hline Dysphania ambrosioides (L.) Mosyakin \& Clemants & 170 & epazote & $\mathrm{H}$ & ARV \\
\hline Gomphrenaserrata L. & 19 & amor de soltero & $\mathrm{H}$ & ARV \\
\hline Iresine diffusa Humb. \& Bonpl. ex Willd. & $130,470,1487$ & velo de novia & $\mathrm{H}$ & ACS, ARV, BTS, VSEC \\
\hline \multicolumn{5}{|l|}{ Anacardiaceae } \\
\hline Astronium graveolens Jacq. & 937,1150 & jobillo & A & ARV, BTP, BTS \\
\hline Mangifera indica L. & 1203 & mango & A & ACS, ARV \\
\hline Spondias mombin L. & 268,858 & jobo & A & ACS, ARV, BTS, BTP \\
\hline Spondias purpurea $\mathrm{L}$. & 766,1439 & ciruela & A & ARV, BTP \\
\hline \multicolumn{5}{|l|}{ Apiaceae } \\
\hline Coriandrum sativum $\mathrm{L}$. & 156 & cilantro de monte & $\mathrm{H}$ & ARV \\
\hline Eryngium foetidum $\mathrm{L}$. & 1142 & cilantro cimarrón & $\mathrm{H}$ & ARV \\
\hline Eryngium nasturtiifolium Juss. ex F. Delaroche & 59 & hierba del sapo & $\mathrm{H}$ & BE, PTZ \\
\hline
\end{tabular}

Apocynaceae

Allamanda cathartica $\mathrm{L}$.

899 copa de oro B

ARV

Asclepias curassavica L.

$8,991,1399$

flor de sangre

$\mathrm{H}$

1203, 1206

platanitos

$\mathrm{H}$

ACS, ARV, BTS, PTZ, VSEC

Asclepias oenotheroides Schltdl. \& Cham.

289,911

volador

ARV, PTZ, VSEC

Aspidosperma megalocarpon Müll. Arg.

401

maravilla

BE, BTP, BTS

Catharanthus roseus (L.) G. Don

402,944

Funastrum clausum (Jacq.) Schltr.

Gonolobus edulis Hemsl.

1105

Metastelma barbigerum Scheele

524

cuayote

ARV

Nerium oleander L.

Plumeria rubra L.

Rauvolfia tetraphylla $\mathrm{L}$.

Tabernaemontana arborea Rose

Tabernaemontana donnell-smithii Rose

839 plumeria
625 mataperros, huesito

1204 A

786, 945 cojón de gato A

ACS, ARV, VSEC
VSEC
ACS, VSEC
ARV
ARV
ACS
BTP

BE, BTP, BTS 
Apéndice. Continuación.

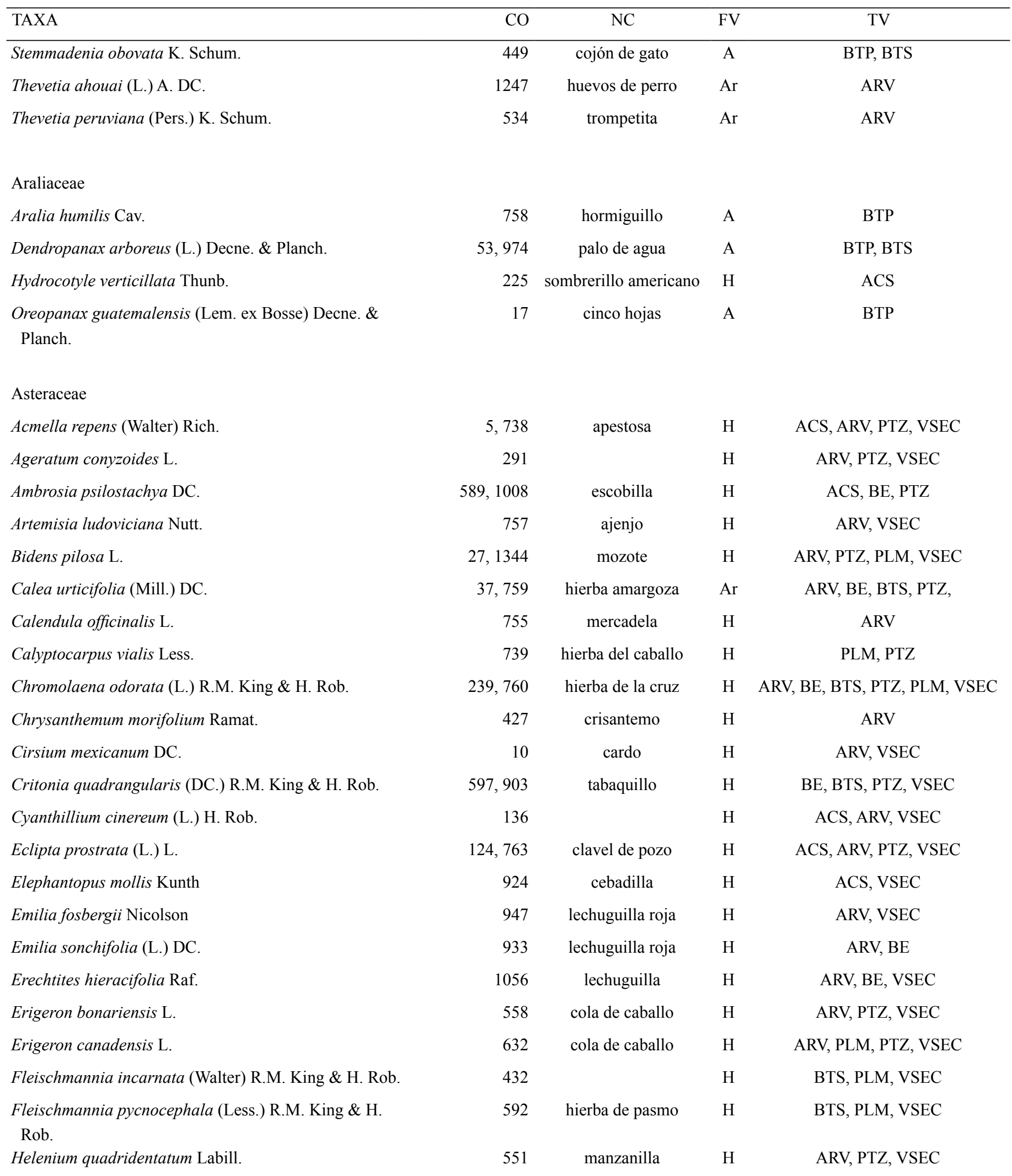


Apéndice. Continuación.

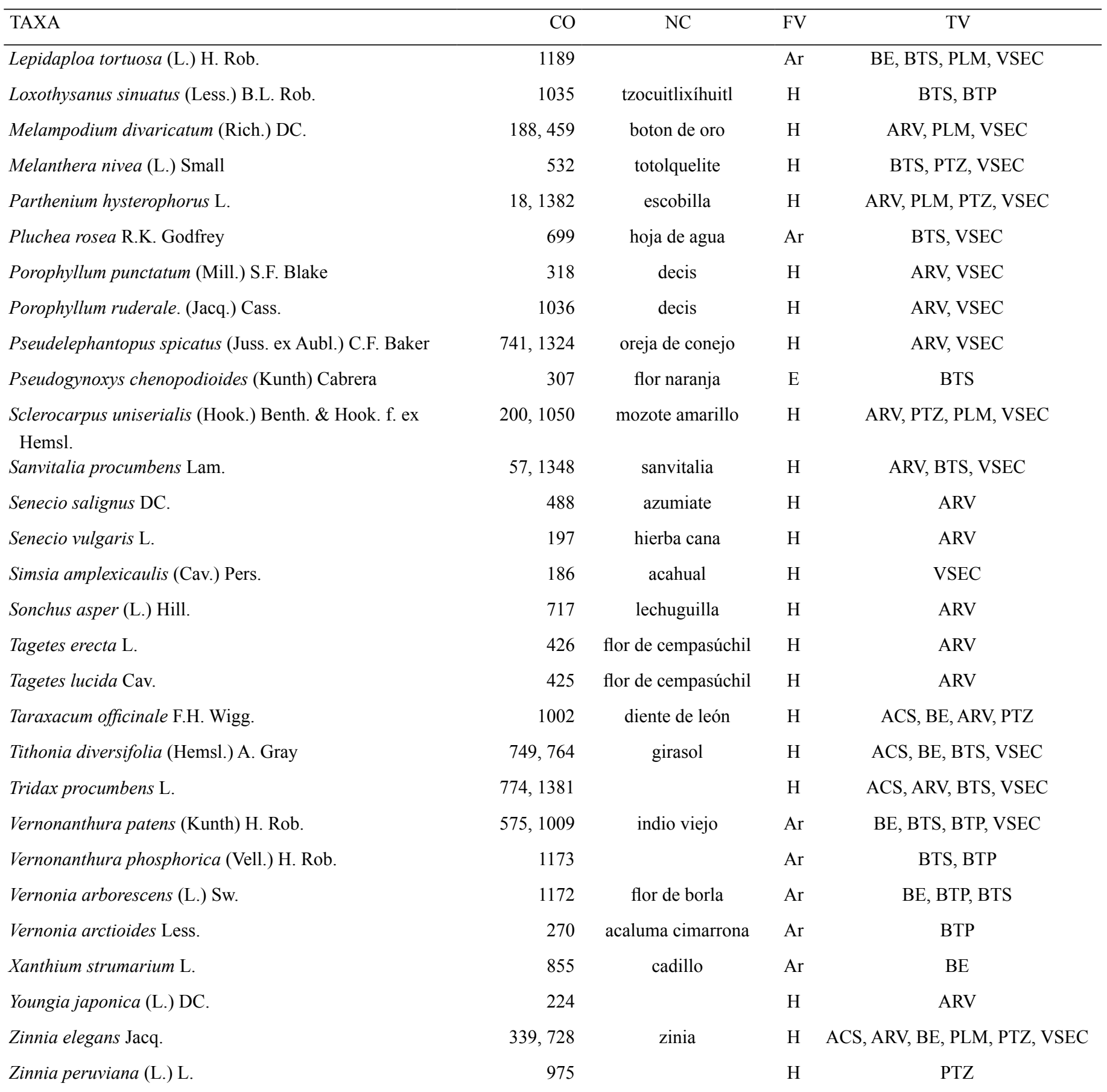

Balanophoraceae

Helosis cayennensis (Sw.) Spreng.

BTP, BT

Balsaminaceae

Impatiens balsamina $\mathrm{L}$. 
Apéndice. Continuación.

\begin{tabular}{|c|c|c|c|c|}
\hline TAXA & $\mathrm{CO}$ & $\mathrm{NC}$ & FV & TV \\
\hline \multicolumn{5}{|l|}{ Basellaceae } \\
\hline Anredera vesicaria (Lam.) C.F. Gaertn. & 687 & yedra & $\mathrm{E}$ & ARV, VSEC \\
\hline \multicolumn{5}{|l|}{ Begoniaceae } \\
\hline Begonia barkeri Knowles \& Westcott & 663 & begonia & $\mathrm{H}$ & BTP \\
\hline Begonia cucullata Willd. & 791 & begonia & $\mathrm{H}$ & BTP \\
\hline Begonia decandra Pav. ex A. DC. & 975,1185 & begonia & $\mathrm{H}$ & BTP, BTS \\
\hline Begonia fusca Liebm. & 1038 & begonia & $\mathrm{H}$ & BTP, BTS \\
\hline Begonia heracleifolia Schltdl. \& Cham. & 997 & begonia & $\mathrm{H}$ & ВTP \\
\hline Begonia multistaminea Burt-Utley & 908 & begonia & $\mathrm{H}$ & BTP, BTS \\
\hline Begonia nelumbonifolia Schltdl. \& Cham. & 909 & begonia & $\mathrm{H}$ & BTP, BTS \\
\hline \multicolumn{5}{|l|}{ Bignoniaceae } \\
\hline Adenocalymma inundatum Mart. ex DC. & 42 & bejuco & $\mathrm{B}$ & BTP, VSEC \\
\hline Amphilophium paniculatum (L.) Kunth & 998,1055 & bejuco prieto & $\mathrm{B}$ & BTS, VSEC \\
\hline Crescentia alata Kunth & 922,767 & huaje & A & BE, BTS, VSEC \\
\hline Dolichandra unguis-cati (L.) L.G. Lohmann & 1040 & uña de murciélago & $\mathrm{B}$ & BTP, BTS, VSEC \\
\hline Mansoa hymenaea (DC.) A.H. Gentry & 1053 & & $\mathrm{~B}$ & ARV, PLM, VSEC \\
\hline Parmentiera aculeata (Kunth) Seem. & 112,1057 & chote & A & ARV, BE, PLM, PTZ, VSEC \\
\hline Pyrostegia venusta (Ker Gawl.) Miers & 902 & bignonia de invierno & $\mathrm{B}$ & ARV \\
\hline Spathodea campanulata P. Beauv. & 926 & tulipán africano & A & ARV, PTZ \\
\hline Tabebuia rosea (Bertol.) DC. & 288 & palo de rosa & A & BTP, PTZ \\
\hline Tecoma stans (L.) Juss. ex Kunth & 529,936 & flor de San Juan & Ar & ARV, BTS \\
\hline \multicolumn{5}{|l|}{ Bixaceae } \\
\hline Cochlospermum vitifolium (Willd.) Spreng. & 994 & pumpo & A & BE, BTS \\
\hline \multicolumn{5}{|l|}{ Boraginaceae } \\
\hline Ehretia anacua (Terán \& Berland.) I.M. Johnst. & 5,904 & raspasombrero & A & BE, BTS, VSEC \\
\hline Heliotropium angiospermum Murray & 12 & rabo de alacrán & $\mathrm{H}$ & ARV, BE, PLM, PTZ, VSEC \\
\hline Heliotropium curassavicum $\mathrm{L}$. & 1162 & rabo de alacrán & $\mathrm{H}$ & ARV, BE, PLM, PTZ, VSEC \\
\hline Heliotropium indicum $\mathrm{L}$. & 999 & rabo de alacrán & $\mathrm{H}$ & ARV, PTZ \\
\hline Heliotropium procumbens Mill. & 714 & rabo de alacrán & $\mathrm{H}$ & ARV, PLM, PTZ, VSEC \\
\hline Nama jamaicensis L. & 164,1186 & & $\mathrm{H}$ & ACS, ARV \\
\hline Wigandia urens (Ruiz \& Pav.) Kunth & 736 & ortiga de tierra caliente & $\mathrm{Ar}$ & ARV \\
\hline
\end{tabular}


Apéndice. Continuación.

\begin{tabular}{lcccc}
\hline TAXA & CO & NC & FV & TV \\
\hline Brassicaceae & & & & \\
Brassica nigra (L.) W.D.J. Koch & 242 & mostaza & H & ARV \\
Lepidium graminifolium L. & 146,585 & berro & H & ARV, PLM, PTZ, VSEC \\
Lepidium virginicum L. & 212 & lentejilla & H & ARV, PLM, PTZ, VSEC
\end{tabular}

Burseraceae

Bursera graveolens (Kunth) Triana \& Planch.

Bursera simaruba (L.) Sarg.

Protium copal (Schltdl. \& Cham.) Engl.

Cactaceae

Acanthocereus pentagonus (L.) Britton \& Rose

Epiphyllum phyllanthus (L.) Haw.

Hylocereus ocamponis (Salm-Dyck) Britton \& Rose

Hylocereus undatus (Haw.) Britton \& Rose

Lophocereus schottii (Engelm.) Britton \& Rose

Nopalea dejecta (Salm-Dyck) Salm-Dyck

Opuntia ficus-indica (L.) Mill.

Opuntia robusta J.C. Wendl.

Rhipsalis baccifera (Sol.) Stearn.

Selenicereus spinulosus (DC.) Britton \& Rose

Campanulaceae

Diastatea micrantha (Kunth) McVaugh

Hippobroma longiflora (L.) G. Don

Lobelia berlandieri A. DC.

Lobelia cardinalis L.

Lobelia cliffortiana L.

Lobelia gruina Cav.

Cannabaceae

Aphananthe monoica (Hemsl.) J.F. Leroy

Celtis iguanaea (Jacq.) Sarg.

Celtis pallida Torr.

Trema micrantha (L.) Blume

$\begin{array}{rccc}857,935 & \text { chaca } & \text { A } & \text { BE, BTP, BTS } \\ 257 & \text { chaca } & \text { A } & \text { BTS } \\ 64 & \text { copal } & \text { A } & \text { BE, BTS }\end{array}$

$\begin{array}{rccc}747,1187 & \text { jacube } & \text { E } & \text { ARV, BTS, VSEC } \\ 463 & & \text { E } & \text { BTP, BTS } \\ 761,1051 & \text { pitaya } & \text { E } & \text { ARV, BE, BTS, PTZ } \\ 445 & \text { pitaya } & \text { E } & \text { BTS } \\ 865 & \text { órgano } & \text { Ar } & \text { ARV, PTZ } \\ 541,679 & \text { nopal } & \text { Ar } & \text { BE, BTP, BTS, PLM, PTZ, VSEC } \\ 748 & \text { nopal } & \text { Ar } & \text { ARV } \\ 817 & \text { nopal patlacho } & \text { Ar } & \text { ARV } \\ 1175 & \text { naturaleza } & \text { E } & \text { BTP, BTS } \\ 587,681 & \text { pitaya nocturna } & \text { E } & \text { BE, BTS, BTP, PLM, PTZ }\end{array}$

$754 \quad \mathrm{H}$

ACS, VSEC

ACS

PTZ

888,1060

cardenal de laguna

ACS, ARC

674,1188

lobelia

$\mathrm{H}$

1045

flor morada

$\mathrm{H}$

ACS, BE, BTP, BTS

ARV, PTZ

254

pipin

A

BE, BTP, BTS

51, 1190

uña de gato

BTP, BTS

543, 931

almez

A

BTP

1133

guasimilla

A

BE, BTP, BTS 
Apéndice. Continuación.

\begin{tabular}{|c|c|c|c|c|}
\hline TAXA & $\mathrm{CO}$ & $\mathrm{NC}$ & FV & TV \\
\hline \multicolumn{5}{|l|}{ Caricaceae } \\
\hline Carica papaya $\mathrm{L}$. & 1249 & papaya & $\mathrm{Ar}$ & ARV \\
\hline Vasconcellea cauliflora (Jacq.) A. DC. & 131 & papaya amargosa & $\mathrm{Ar}$ & ACS, BTS, VSEC \\
\hline \multicolumn{5}{|l|}{ Casuarinaceae } \\
\hline Casuarina equisetifolia $\mathrm{L}$. & 787 & pinabeto & A & ARV, PTZ \\
\hline \multicolumn{5}{|l|}{ Celastraceae } \\
\hline Pristimera celastroides (Kunth) A.C. Sm. & 535,602 & & $\mathrm{Ar}$ & BE, BTS, BTP, PTZ \\
\hline \multicolumn{5}{|l|}{ Cleomaceae } \\
\hline Polanisia dodecandra (L.) DC. & 772 & pegajosa & $\mathrm{H}$ & ARV, VSEC \\
\hline \multicolumn{5}{|l|}{ Combretaceae } \\
\hline Terminalia catappa $\mathrm{L}$. & 523 & almendro & A & BE, BTS, BTP \\
\hline \multicolumn{5}{|l|}{ Connaraceae } \\
\hline Rourea glabra Kunth & 1046 & & $\mathrm{Ar}$ & BTS \\
\hline \multicolumn{5}{|l|}{ Convolvulaceae } \\
\hline Convolvulus nodiflorus Desr. & 1047 & remulatero & $\mathrm{B}$ & ARV, PLM, PTZ, VSEC \\
\hline Evolvulus alsinoides (L.) L. & 362 & ojitos azules & $\mathrm{H}$ & ACS \\
\hline Evolvulus nummularius (L.) L. & 718 & & $\mathrm{H}$ & $\mathrm{ACS}, \mathrm{BE}$ \\
\hline Evolvulus prostratus B.L. Rob. & 243 & & $\mathrm{H}$ & ARV, BE, PTZ \\
\hline Ipomoea batatas (L.) Lam. & 565 & camote & $\mathrm{B}$ & ARV \\
\hline Ipomoea cairica (L.) Sweet & 801 & campanilla & $\mathrm{B}$ & PTZ, VSEC \\
\hline Ipomoea carnea Jacq. & 781 & trompetita & $\mathrm{B}$ & ARV, BE, BTS \\
\hline Ipomoea cholulensis Kunth & 361 & & $\mathrm{~B}$ & ARV, VSEC \\
\hline Ipomoea fistulosa Mart. ex Choisy & 1209 & & $\mathrm{~B}$ & ARV, VSEC \\
\hline Ipomoea indica (Burm.) Merr. & 211 & trompetita morada & $\mathrm{B}$ & ACS, ARV, VSEC \\
\hline Ipomoea minutiflora (M. Martens \& Galeotti) House & 593 & & $\mathrm{~B}$ & PLM, PTZ \\
\hline Ipomoea purpurea (L.) Roth & 1001 & campanitas & $\mathrm{B}$ & ARV, BE, PLM, PTZ, VSEC \\
\hline Ipomoea quamoclit $\mathrm{L}$. & 863 & & $\mathrm{~B}$ & ARV \\
\hline Ipomoea squamosa Choisy & 711,932 & & $\mathrm{~B}$ & BE, BTP, BTS \\
\hline Ipomoea trifida (Kunth) G. Don & 907 & & $\mathrm{~B}$ & PLM, PTZ, VSEC \\
\hline
\end{tabular}


Apéndice. Continuación.

\begin{tabular}{|c|c|c|c|c|}
\hline TAXA & $\mathrm{CO}$ & $\mathrm{NC}$ & FV & TV \\
\hline Ipomoea tiliacea (Willd.) Choisy & 411 & quiebraplato & $\mathrm{B}$ & BTP \\
\hline Ipomoea triloba $\mathrm{L}$. & 1124 & & $\mathrm{~B}$ & $\begin{array}{c}\text { ACS, ARV, BE, BTS, BTP, PLM, } \\
\text { VSEC }\end{array}$ \\
\hline Ipomoea variabilis (Schltdl. \& Cham.) Choisy & 216 & & $\mathrm{~B}$ & BE, BTP, VSEC \\
\hline Jacquemontia verticillata (L.) Urb. & 533,1048 & & $\mathrm{~B}$ & BE, PLM, PTZ,VSEC \\
\hline Merremia umbellata (L.) Hallier f. & 3 & & $\mathrm{~B}$ & ARV, VSEC \\
\hline Merremia quinquefolia (L.) Hallier f. & 694,1192 & bejuco cinco hojas & $\mathrm{B}$ & ARV, VSEC \\
\hline Operculina pinnatifida (Kunth) O’Donell & 522,1049 & & $\mathrm{~B}$ & ARV, BE, BTP, VSEC \\
\hline Turbina corymbosa (L.) Raf. & 1023 & & $\mathrm{~B}$ & ACS, BTP, BTS, VSEC \\
\hline
\end{tabular}

Crassulaceae

Kalanchoe blossfeldiana Poelln.

$452 \quad$ kalanchoe

$\mathrm{H}$

ARV

Cucurbitaceae

Cayaponia attenuata (Hook. \& Arn.) Cogn.

Cucumis dipsaceus Ehrenb. ex Spach

Cucurbita argyrosperma $\mathrm{K}$. Koch

Luffa cylindrica (L.) M. Roem.

Melothria pendula L.

Momordica charantia L.

Sechium edule (Jacq.) Sw.

Sicydium tamnifolium (Kunth) Cogn.

Cytinaceae

Bdallophytum americanum (R. Br.) Eichler ex Solms

Dilleniaceae

Curatella americana $\mathrm{L}$.

Ericaceae

Chimaphila maculata (L.) Pursh

Ebenaceae

Diospyros nigra (J.F. Gmel.) Perr.
720
579,1139

hojamán

Ar

BE, BTS, PLM, PTZ, VSEC

ACS, ARV, BTS, PLM, PTZ, VSEC
ACS, VSEC
ARV
ACS, ARV
ACS, ARV, BE, BTS, PLM, VSEC
VSEC
ARV
BTP

BTS, BTP

516,784

$\mathrm{P}$

BTP, BTS 
Apéndice. Continuación.

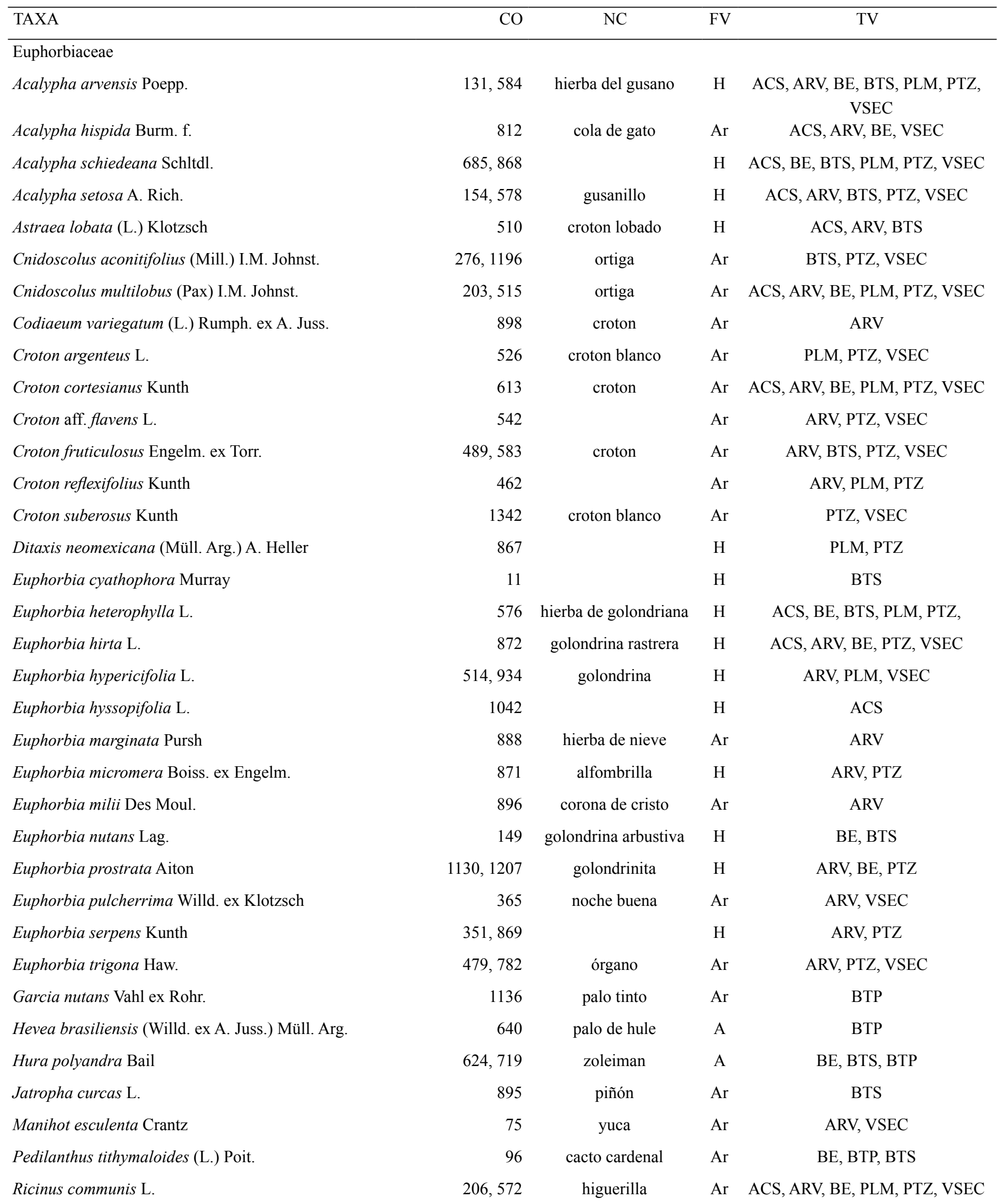


Apéndice. Continuación.

\begin{tabular}{|c|c|c|c|c|}
\hline TAXA & $\mathrm{CO}$ & $\mathrm{NC}$ & FV & TV \\
\hline \multicolumn{5}{|l|}{ Fabaceae } \\
\hline Acacia cornigera (L.) Willd. & 9 & cornizuelo & Ar & ARV, BE, PLM, PTZ, VSEC \\
\hline Acacia farnesiana (L.) Willd. & 98 & huizache & $\mathrm{Ar}$ & PTZ \\
\hline Acacia riparia Kunth & 131 & carbonera & $\mathrm{Ar}$ & ACS \\
\hline Acacia schaffneri (S. Watson) F.J. Herm. & 136 & huizache espinudo & $\mathrm{Ar}$ & ARV, PTZ \\
\hline Acacia sphaerocephala Cham. \& Schltdl. & 1211 & cornizuelo & $\mathrm{Ar}$ & $\mathrm{BE}$ \\
\hline Aeschynomene americana $\mathrm{L}$. & 486,1212 & & $\mathrm{H}$ & ARV, PLM, PTZ \\
\hline Albizia lebbeck (L.) Benth. & 528 & casia amarilla & A & BTS \\
\hline Arachis pintoi Krapov. \& W.C. Greg. & 1140 & cacahuate & $\mathrm{H}$ & ARV \\
\hline Bauhinia divaricata $\mathrm{L}$. & 104 & pata de vaca & $\mathrm{Ar}$ & $\begin{array}{c}\text { ACS, ARV, BE BTS, PLM, PTZ, } \\
\text { VSEC }\end{array}$ \\
\hline Bauhinia variegata $\mathrm{L}$. & 503 & pata de vaca & $\mathrm{Ar}$ & ARV \\
\hline Caesalpinia mexicana A. Gray & 513,530 & & $\mathrm{Ar}$ & ACS, PTZ, VSEC \\
\hline Caesalpinia pulcherrima (L.) Sw. & 901 & tabachín & $\mathrm{Ar}$ & ARV, PLM, VSEC \\
\hline Cajanus cajan (L.) Huth & 457 & frijolillo & $\mathrm{Ar}$ & ARV, VSEC \\
\hline Calliandra grandiflora (L'Hér.) Benth. & 7 & cabellito de ángel & $\mathrm{Ar}$ & $\begin{array}{c}\text { ACS, ARV, BE, BTS, PLM, PTZ, } \\
\text { VSEC }\end{array}$ \\
\hline Canavalia pubescens Hook. \& Arn. & 190 & canavalia & $\mathrm{B}$ & ACS, ARV, BTS, VSEC \\
\hline Canavalia rosea (Sw.) DC. & 860 & & B & BE, ВTP \\
\hline Canavalia septentrionalis J.D. Sauer & 219 & canavalia & B & BE, BTP \\
\hline Canavalia villosa Benth. & 577 & gallinita & B & BTS, VSEC \\
\hline Cassia fistula $\mathrm{L}$. & 334 & macana & A & ARV, BTS \\
\hline Cassia occidentalis L. & 563 & frijolillo & $\mathrm{Ar}$ & ARV, PLM, PTZ \\
\hline Centrosema angustifolium (Kunth) Benth. & 511,742 & & B & ACS, ARV, BE, BTS, BTP \\
\hline Centrosema plumieri (Turpin ex Pers.) Benth. & 571,740 & & B & ACS, ARV, BTS, PLM, PTZ, VSEC \\
\hline Centrosema pubescens Benth. & 142 & bejuco trifoliado & B & BE, BTP \\
\hline Centrosema virginianum (L.) Benth. & 748 & zapatito de la virgen & B & BTP \\
\hline Chamaecrista absus (L.) H.S. Irwin \& Barneby & 745 & & $\mathrm{H}$ & PLM, PTZ \\
\hline Cojoba arborea (L.) Britton \& Rose & 845 & coralillo & A & ACS, BTS, PLM, PTZ \\
\hline Cologania broussonetii (Balb.) DC. & 954 & bejuco & B & PLM, PTZ \\
\hline Crotalaria incana $\mathrm{L}$. & 152,509 & frijolillo & $\mathrm{H}$ & ARV, PTZ, VSEC \\
\hline Crotalaria retusa $\mathrm{L}$. & 559 & frijolillo & $\mathrm{H}$ & $\begin{array}{c}\text { ACS, ARV, BE, BTS, PLM, PTZ, } \\
\text { VSEC }\end{array}$ \\
\hline Delonix regia (Bojer ex Hook.) Raf. & 305 & frambroyán & A & ARV, PTZ \\
\hline Desmodium incanum (Sw.) DC. & 1054 & pega pega & $\mathrm{H}$ & BE, BTP, BTS, PTZ, VSEC \\
\hline Desmodium tortuosum (Sw.) DC. & 1213 & pega pega & $\mathrm{H}$ & ACS, BE, BTS, VSEC \\
\hline Desmodium triflorum (L.) DC. & 1224 & & $\mathrm{H}$ & ARV, PTZ \\
\hline
\end{tabular}


Apéndice. Continuación.

\begin{tabular}{|c|c|c|c|c|}
\hline TAXA & $\mathrm{CO}$ & $\mathrm{NC}$ & FV & TV \\
\hline Diphysa americana (Mill.) M. Sousa & 1257 & quebracho & A & ARV, PTZ \\
\hline Diphysa carthagenensis Jacq. & 1253 & quebracho & A & ARV, BE, BTS, VSEC \\
\hline Ebenopsis ebano (Berland.) Barneby \& J.W. Grimes & 1239 & ébano & A & ARV, PTZ \\
\hline Enterolobium cyclocarpum (Jacq.) Griseb. & 568,644 & origuelo & A & ACS, BE, BTS, BTP, PTZ, VSEC \\
\hline Erythrina americana Mill. & 458 & pichoco & A & ARV, BTS, VSEC \\
\hline Erythrina berteroana Urb. & 517 & pichoco rosa & A & $\mathrm{BE}, \mathrm{BTS}$ \\
\hline Galactia striata (Jacq.) Urb. & 491 & bejuco & B & PTZ \\
\hline Gliricidia sepium (Jacq.) Kunth ex Walp. & 537 & palo de sol & A & $\begin{array}{c}\text { ACS, ARV, BE, BTS, PLM, PTZ, } \\
\text { VSEC }\end{array}$ \\
\hline Indigofera jamaicensis Spreng. & 826 & & $\mathrm{Ar}$ & BE, BTS, BTP \\
\hline Inga vera Willd. & 174 & chalahuite & A & ACS \\
\hline Leucaena leucocephala (Lam.) de Wit & 770 & leucaena & $\mathrm{Ar}$ & ARV, PTZ, VSEC \\
\hline Leucaena pulverulenta (Schltdl.) Benth. & 497,588 & tepehuaje & A & ARV, PTZ, VSEC \\
\hline Macroptilium atropurpureum (Moc. \& Sessé ex DC.) Urb. & 853 & conchito & B & ACS, ARV, PTZ, VSEC \\
\hline Macroptilium lathyroides (L.) Urb. & 805 & & $\mathrm{~B}$ & ARV, VSEC \\
\hline Mimosa albida Humb. \& Bonpl. ex Willd. & 1047 & uña de gato & B & ACS, BE, PTZ, VSEC \\
\hline Mimosa pudica $\mathrm{L}$. & 113 & dormilona & $\mathrm{H}$ & ACS, ARV, PTZ, VSEC \\
\hline Mimosa quadrivalvis $\mathrm{L}$. & 506,1148 & dormilona & $\mathrm{Ar}$ & ARV, PTZ, VSEC \\
\hline Mucuna pruriens (L.) DC. & 216 & pica pica & B & ACS, ARV, VSEC \\
\hline Neptunia lutea (Leavenw.) Benth. & 294 & uña de gato & $\mathrm{H}$ & ACS, ARV, PTZ \\
\hline Neptunia plena (L.) Benth. & 1152 & & $\mathrm{H}$ & ARV, BE, VSEC \\
\hline Nissolia fruticosa Jacq. & 21 & & B & BTS, VSEC \\
\hline Parkinsonia aculeata L. & 1314 & palo verde & A & ARV, PTZ \\
\hline Phaseolus lunatus L. & 454 & frijol criollo & B & ARV \\
\hline Phaseolus vulgaris L. & 819 & frijol & $\mathrm{H}$ & ARV \\
\hline Piscidia carthagenensis Jacq. & 103 & chijol & A & BE, BTP, BTS \\
\hline Pithecellobium dulce (Roxb.) Benth. & 929 & humo & A & ACS, ARV, PLM, PTZ, VSEC \\
\hline Pithecellobium insigne Micheli ex Donn. Sm. & 554 & & A & ACS, PTZ \\
\hline Rhynchosia longeracemosa M. Martens \& Galeotti & 336 & & B & PLM, PTZ \\
\hline Rhynchosia minima (L.) DC. & 614 & & B & ARV, PTZ \\
\hline Rhynchosia precatoria (Humb. \& Bonpl. ex Willd.) DC. & 280 & & B & ARV, PLM, PTZ \\
\hline Senna atomaria (L.) H.S. Irwin \& Barneby & 453 & vainillo & A & BTS \\
\hline Senna occidentalis (L.) Link & 390,505 & frijolillo & $\mathrm{Ar}$ & ACS, ARV, VSEC \\
\hline Senna pallida (Vahl) H.S. Irwin \& Barneby & 756 & & Ar & ARV, VSEC \\
\hline Vatairea lundellii (Standl.) Killip ex Record & 960 & & A & ВТP \\
\hline $\begin{array}{l}\text { Vigna adenantha (G. Mey.) Maréchal, Mascherpa \& } \\
\text { Stainier }\end{array}$ & 480 & bejuco frijolillo & $\mathrm{B}$ & ARV, VSEC \\
\hline
\end{tabular}


Apéndice. Continuación.

\begin{tabular}{lrrrr}
\hline TAXA & CO & NC & FV & TV \\
\hline Vigna luteola (Jacq.) Benth. & 1296 & bejuco frijolillo & B & ARV, VSEC \\
Vigna unguiculata (L.) Walp. & 442 & & B & VSEC
\end{tabular}

Fagaceae

Quercus oleoides Schltdl. \& Cham.

Gentianaceae

Eustoma exaltatum (L.) Salisb. ex G. Don

Hydroleaceae

Hydrolea spinosa L.

Lamiaceae

Gmelina arborea Roxb.

Hedeoma drummondii Benth.

Hyptis capitata Jacq.

Hyptis pectinata (L.) Poit.

Hyptis suaveolens (L.) Poit.

Hyptis verticillata Jacq.

Leonotis aff. leonurus (L.) R. Br.

Leonotis nepetifolia (L.) R. Br.

Leonurus cardiaca L.

Mentha spicata L.

Ocimum basilicum L.

Ocimum campechianum Mill.

Plectranthus scutellarioides (L.) R. Br.

Salvia coccinea Buc'hoz ex Etl.

Salvia officinalis L.

Loasaceae

Gronovia scandens L.

Mentzelia aspera L.

Loganiaceae

Spigelia anthelmia L.
287

encino

A

$\mathrm{BE}$

507

violeta

$\mathrm{H}$

ARV, PTZ

666 hydrolea espinosa

$\mathrm{H}$

ACS, BTP

504,822

746

melina

poleo

A

$\mathrm{H}$

$\mathrm{H}$

$\mathrm{Ar}$

744

453

chan

$\mathrm{H}$

94

456

202

733

429

430

24

910

778

660

mano de león

agripalma

hierbabuena

albahaca

albahaca de monte

Ar

Ar

$\mathrm{H}$

$\mathrm{H}$

$\mathrm{H}$

$\mathrm{H}$

$\mathrm{H}$

$\mathrm{H}$

$\mathrm{H}$

$\mathrm{H}$

salvia

701, 1155

1216

ortiga

pegaropa

B

H

ACS, VSEC

ARV, VSEC

ARV

ARV

BTP, BTS

ARV

ARV, VSEC

ACS, ARV, VSEC 
Apéndice. Continuación.

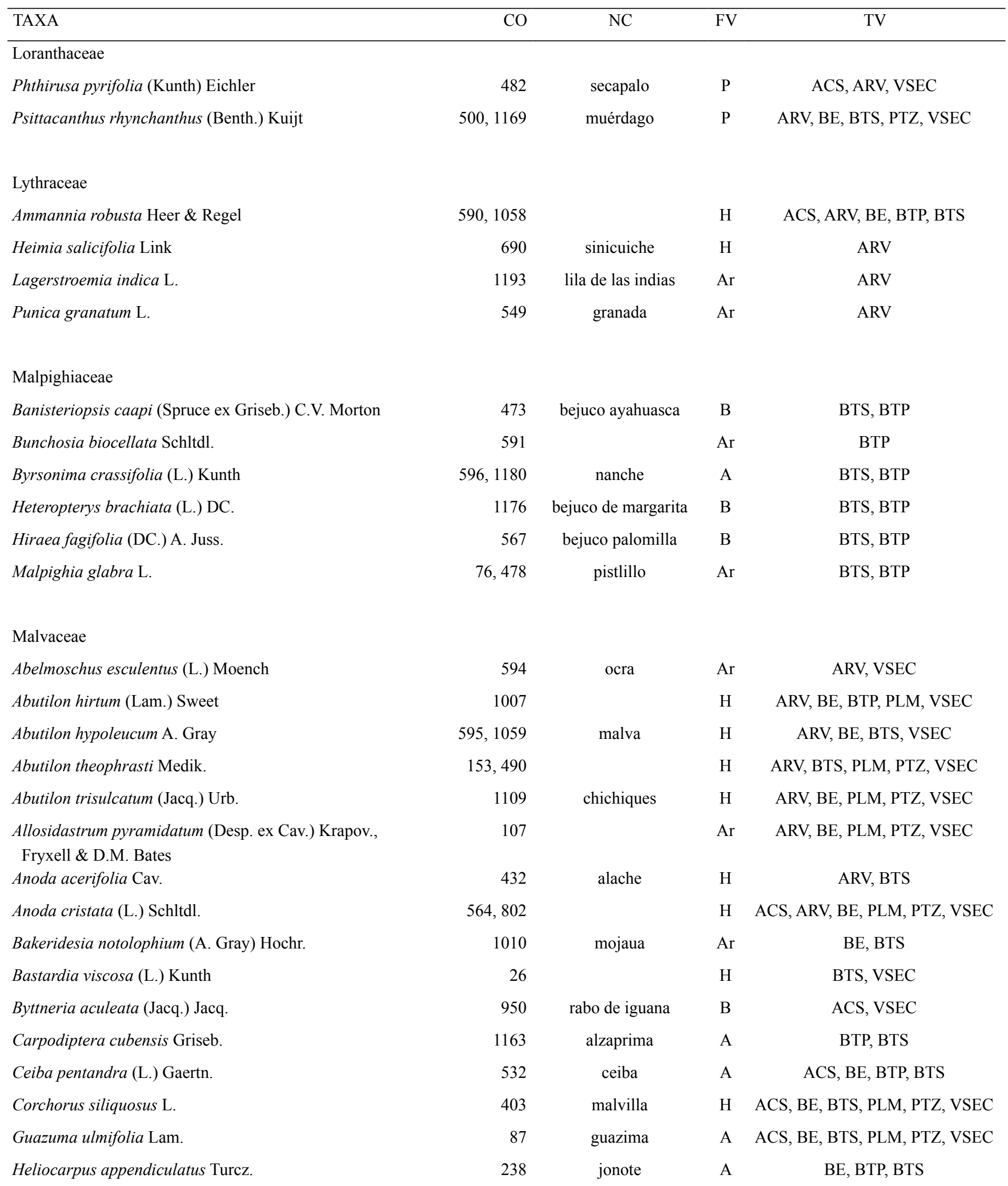


Apéndice. Continuación.

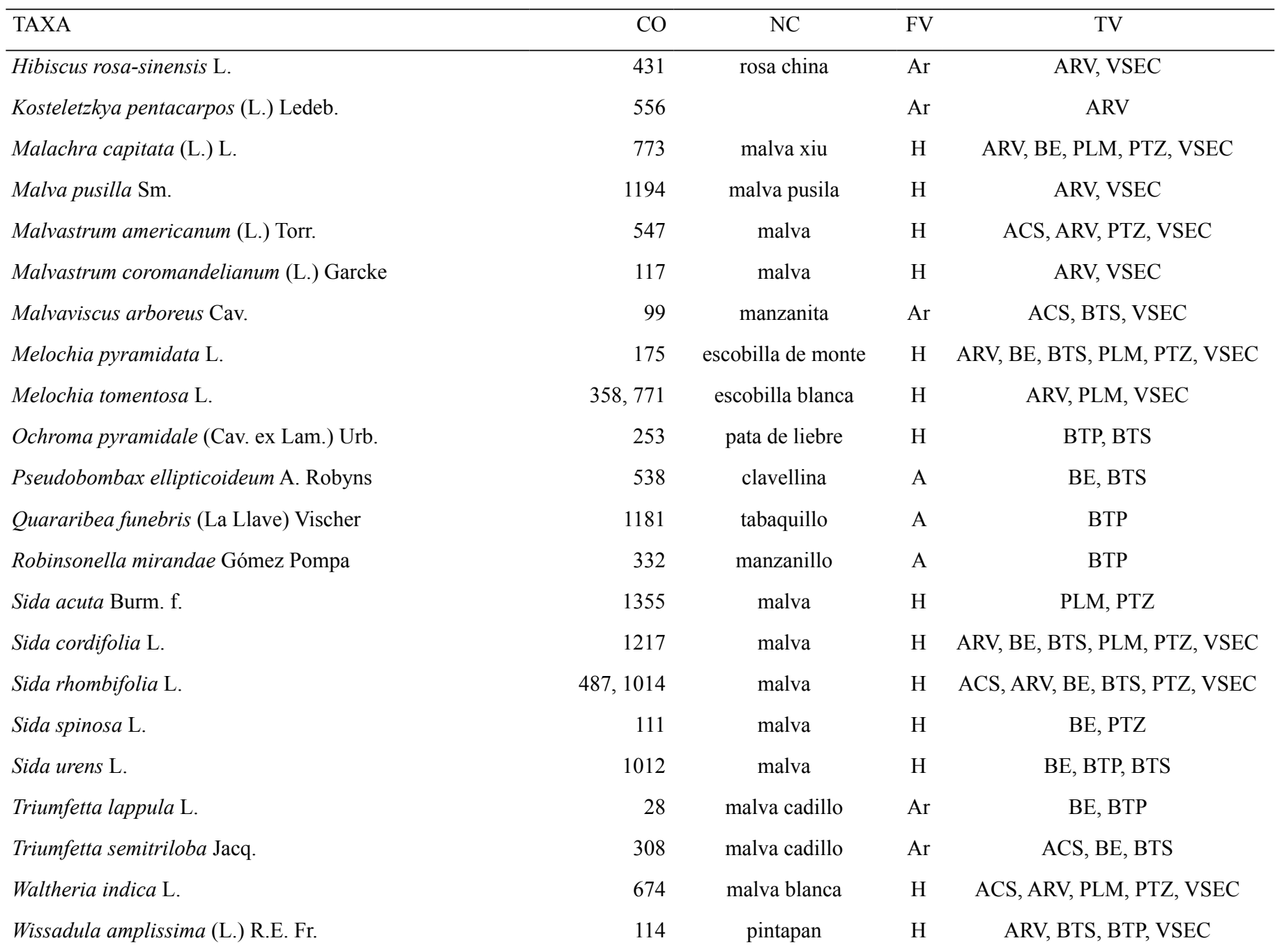

Meliaceae

Azadirachta indica A. Juss.

Cedrela odorata L.

Guarea glabra Vahl

Swietenia macrophylla King

Trichilia havanensis Jacq.

Trichilia hirta L.

Menispermaceae

Cissampelos fasciculata Benth.

Cissampelos pareira $\mathrm{L}$.

Cissampelos tropaeolifolia DC.
444
477

536 tortilla tapasapos

811
574

1179

446

604

58

cucharillo

tapaqueso

néem

cedro

cedrillo

caoba

A

A

A

A

A

B

B

B
ARV

ARV, BE, BTP, BTS

BTP

ARV, BE, BTP, BTS

BTP, BTS

BTP, BTS 
Apéndice. Continuación.

\begin{tabular}{|c|c|c|c|c|}
\hline TAXA & $\mathrm{CO}$ & $\mathrm{NC}$ & FV & TV \\
\hline \multicolumn{5}{|l|}{ Moraceae } \\
\hline Brosimum alicastrum $\mathrm{Sw}$. & 396 & ramón & A & BTP, BTS \\
\hline Brosimum lactescens (S. Moore) C.C. Berg & 371,499 & & A & BTP, BTS \\
\hline Castilla elastica Sessé & 114 & palo volador, hule & A & BE, BTS, BTP \\
\hline Ficus aurea Nutt. & 810 & higuero & A & ARV, BTP, VSEC \\
\hline Ficus cotinifolia Kunth & 848 & higuero & A & ACS, BTP, BTS \\
\hline Ficus crocata (Miq.) Mart. ex Miq. & 661 & higuero & A & BTS \\
\hline Ficus elastica Roxb. ex Hornem. & 1251 & higuero & A & ARV \\
\hline Ficus insipida Willd. & 493,783 & higuero & A & ACS, BTP, BTS \\
\hline Ficus obtusifolia Kunth & 980 & higuero & A & BTS \\
\hline Ficus pertusa L. f. & 443,702 & higuero & A & ACS, BTP, BTS \\
\hline Maclura tinctoria (L.) D. Don ex Steud. & 562,1099 & mora & A & ACS, VSEC \\
\hline Trophis racemosa (L.) Urb. & 1117 & campanilla & A & BTP \\
\hline \multicolumn{5}{|l|}{ Muntingiaceae } \\
\hline Muntingia calabura $\mathrm{L}$. & 435 & puan & A & ACS, ARV, BE, BTS \\
\hline \multicolumn{5}{|l|}{ Myrtaceae } \\
\hline Eugenia acapulcensis Steud. & 1016 & pistlillo & $\mathrm{Ar}$ & BE, BTP, BTS \\
\hline Eugenia capuli (Schltdl. \& Cham.) Hook. \& Arn. & 30 & pistlillo & $\mathrm{Ar}$ & BE, BTP, BTS \\
\hline Pimenta dioica (L.) Merr. & 79,600 & pimienta & A & BE, BTP, BTS \\
\hline Psidium guajava $\mathrm{L}$. & 469 & guayaba & A & ACS, BE, BTS, PTZ \\
\hline \multicolumn{5}{|l|}{ Nyctaginaceae } \\
\hline Boerhavia coccinea Mill. & 324 & & $\mathrm{H}$ & ARV, VSEC \\
\hline Boerhavia erecta $\mathrm{L}$. & 352 & & $\mathrm{H}$ & ARV, PLM \\
\hline Bougainvillea buttiana Holttum \& Standl. & 364 & bugambilia & $\mathrm{Ar}$ & ARV \\
\hline Bougainvillea glabra Choisy & 463 & bugambilia & $\mathrm{Ar}$ & ARV \\
\hline Bougainvillea spectabilis Willd. & 1149 & bugambilia & $\mathrm{Ar}$ & ARV \\
\hline Mirabilis jalapa $\mathrm{L}$. & 448 & maravilla & $\mathrm{H}$ & ACS, ARV \\
\hline Pisonia aculeata $\mathrm{L}$. & 498,1195 & uña de gato & $\mathrm{Ar}$ & BTS, VSEC \\
\hline \multicolumn{5}{|l|}{ Oleaceae } \\
\hline Forestiera rhamnifolia Griseb. & 400 & & $\mathrm{Ar}$ & ВTP \\
\hline
\end{tabular}


Acta Botanica Mexicana 121: 83-124 Octubre 2017

Apéndice. Continuación.

\begin{tabular}{|c|c|c|c|c|}
\hline TAXA & $\mathrm{CO}$ & $\mathrm{NC}$ & FV & TV \\
\hline \multicolumn{5}{|l|}{ Onagraceae } \\
\hline Ludwigia octovalvis (Jacq.) P.H. Raven & 132 & & $\mathrm{H}$ & ACS \\
\hline Oenothera rosea L'Hér. ex Aiton & 1254 & hierba del golpe & $\mathrm{H}$ & BTP, BTS \\
\hline \multicolumn{5}{|l|}{ Oxalidaceae } \\
\hline Averrhoa carambola L. & 420 & carambola & A & ARV \\
\hline Oxalis articulata Savigny & 272 & trébol & $\mathrm{H}$ & ARV \\
\hline Oxalis curniculata L. & 853 & agritos & $\mathrm{H}$ & ARV \\
\hline
\end{tabular}

Papaveraceae

Argemone mexicana L.

$116,630 \quad$ cardo

H ACS, ARV, BE, PLM, PTZ, VSEC

Passifloraceae

Passiflora edulis Sims

Passiflora foetida L.

Passiflora laurifolia L.

Passiflora sexocellata Schltdl.

$\begin{array}{rccc}866 & \text { maracuyá } & \text { B } & \text { BTP } \\ 519 & & \text { B } & \text { BTS, BTP } \\ 612 & \text { maracuyá } & \text { B } & \text { BTP } \\ 91,495 & \text { hoja de murciélago } & \text { B } & \text { BE, BTS, BTP } \\ & & & \\ 829 & \text { ajonjolí } & \text { Ar } & \text { ACS, ARV } \\ & & & \\ 650,705 & \text { rosillo } & \text { H } & \text { ACS, ARV, BE, PLM, PTZ, VSEC }\end{array}$

Phyllanthus niruri L.

$125,650,705 \quad$ rosillo

H ACS, ARV, BE, PLM, PTZ, VSEC

Petiveriaceae

Petiveria alliacea $\mathrm{L}$.

404 cola de tejón $\mathrm{H}$

ACS, ARV, VSEC

Rivina humilis L.

496, 1022

coralillo

Phytolacacceae

Agdestis clematidea Moc. \& Sessé ex DC.

1066

B

ACS, BTS

Plantaginaceae
Bacopa monnieri (L.) Wettst.

121

846

Limnophila indica (L.) Druce

Mecardonia procumbens (Mill.) Small

Plantago major L.

230 hoja de quebranto $\mathrm{H}$

889 llantén H

441,629

Russelia coccinea (L.) Wettst.
ACS, BE, BTP, BTS, VSEC 
Apéndice. Continuación.

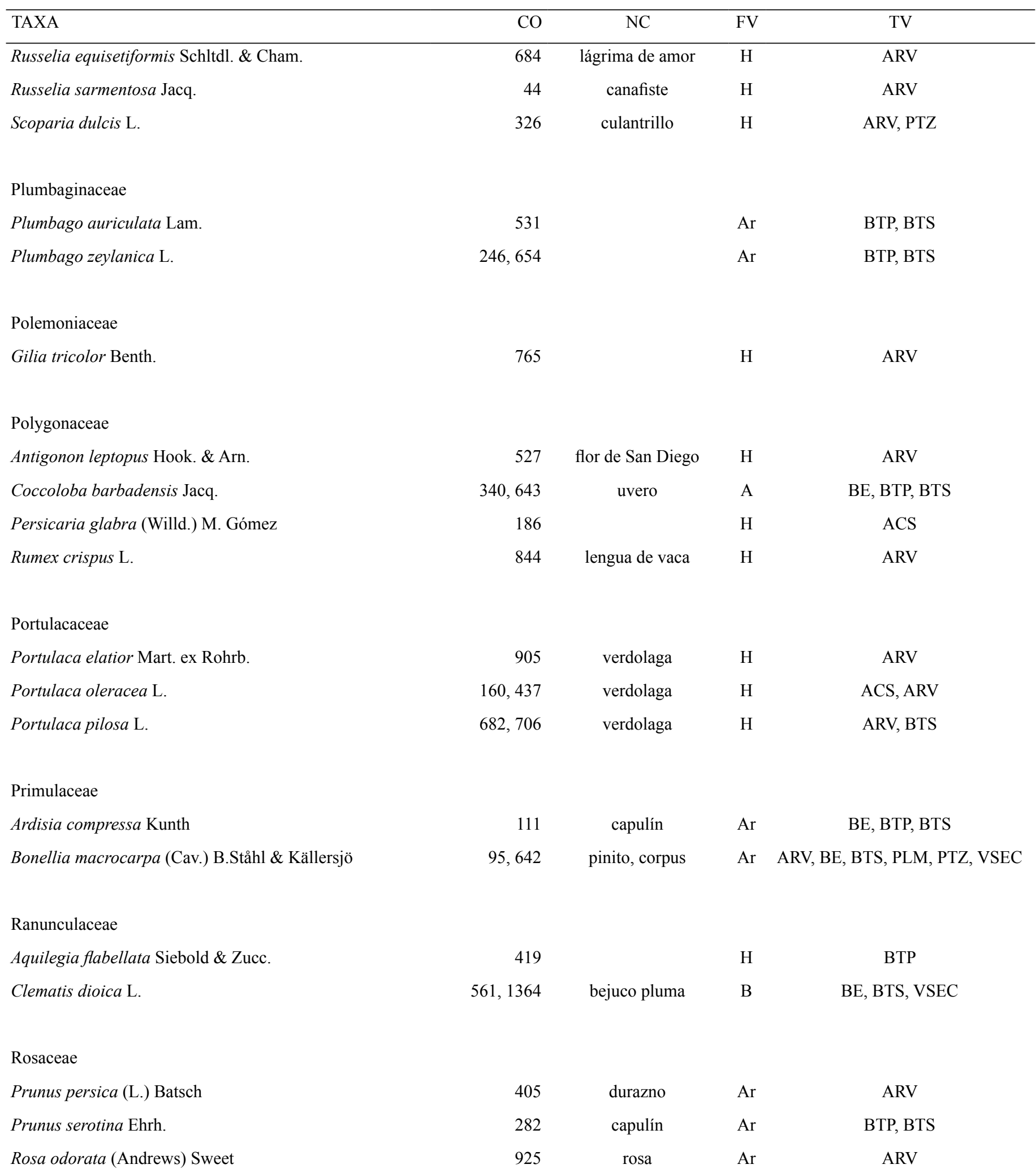


Apéndice. Continuación.

\begin{tabular}{|c|c|c|c|c|}
\hline TAXA & $\mathrm{CO}$ & $\mathrm{NC}$ & FV & TV \\
\hline \multicolumn{5}{|l|}{ Rubiaceae } \\
\hline Blepharidium guatemalense Standl. & 66,655 & & A & BTP, BTS \\
\hline Calycophyllum candidissimum (Vahl) DC. & 788 & & A & BTP, BTS \\
\hline Coffea arabica $\mathrm{L}$. & 753 & café & $\mathrm{Ar}$ & ARV \\
\hline Exostema mexicanum A. Gray & 651 & & A & BTP \\
\hline Galium uncinulatum DC. & 557 & & $\mathrm{H}$ & BTP \\
\hline Gardenia jasminoides J. Ellis & 634 & gardenia & $\mathrm{Ar}$ & ARV \\
\hline Hamelia patens Jacq. & 49,436 & tres hojitas & $\mathrm{Ar}$ & ACS, BE, BTS, PLM, PTZ, VSEC \\
\hline Ixora coccinea $\mathrm{L}$. & 418 & morir amando & $\mathrm{Ar}$ & ARV \\
\hline Psychotria alba Ruiz \& Pav. & 698 & psicotria & $\mathrm{H}$ & BTP \\
\hline Psychotria carthagenensis Jacq. & 302 & & $\mathrm{Ar}$ & BTP \\
\hline Psychotria erythrocarpa Schltdl. & 100,639 & & $\mathrm{Ar}$ & BTP, BTS \\
\hline Psychotria hoffmannseggiana (Schult.) Müll. Arg. & 89,627 & & $\mathrm{H}$ & BTP, BTS \\
\hline Psychotria mexiae Standl. & 55,601 & & $\mathrm{Ar}$ & ACS, BTP, BTS \\
\hline Randia armata (Sw.) DC. & 34 & cruceta & $\mathrm{Ar}$ & ARV, BE, BTS, PLM, PTZ, VSEC \\
\hline Randia obcordata S. Watson & 59 & cruceta & $\mathrm{Ar}$ & ARV, BTP, BTS, VSEC \\
\hline Richardiascabra L. & 425 & golondrina blanca & $\mathrm{H}$ & ACS, ARV, PTZ \\
\hline Uncaria tomentosa (Willd. ex Schult.) DC. & 494 & uña de gato & B & ACS, BE, BTS, BTP, VSEC \\
\hline
\end{tabular}

Rutaceae

Casimiroa edulis La Llave \& Lex.

1375

Citrus limon (L.) Osbeck

Citrus maxima (Burm.) Merr.

Citrus reticulata Blanco

Citrus sinensis (L.) Osbeck

Murraya paniculata (L.) Jack.

Zanthoxylum fagara (L.) Sarg.

Salicaceae

Casearia corymbosa Kunth

Casearia nitida Jacq.

Populus mexicana Wesm. ex DC.

Salix humboldtiana Willd.

Salix taxifolia Kunth

Xylosma flexuosa (Kunth) Hemsl.

$\begin{array}{rccc}434,586 & \text { botoncillo } & \mathrm{A} & \text { BE, BTP, BTS } \\ 1174 & \text { chamiso } & \mathrm{Ar} & \text { BTP } \\ 737 & \text { álamo } & \mathrm{A} & \text { ACS } \\ 608 & \text { sauce } & \mathrm{A} & \text { ACS } \\ 208 & \text { sauce enano } & \mathrm{Ar} & \text { ACS }\end{array}$

943, 656 granadillo Ar $\quad$ BE, PLM, PTZ 
Apéndice. Continuación.

\begin{tabular}{|c|c|c|c|c|}
\hline TAXA & $\mathrm{CO}$ & $\mathrm{NC}$ & $\mathrm{FV}$ & TV \\
\hline Xylosma panamensis Turcz. & 1053 & & $\mathrm{Ar}$ & BTS \\
\hline Zuelania guidonia (Sw.) Britton \& Millsp. & 1182 & & A & BTS, BTP \\
\hline \multicolumn{5}{|l|}{ Santalaceae } \\
\hline Phoradendron leucarpum (Raf.) Reveal \& M.C. Johnst. & 799 & muérdago & $\mathrm{P}$ & ARV, BE, PLM, PTZ \\
\hline Phoradendron quadrangulare (Kunth) Griseb. & 477 & secapalo & $\mathrm{P}$ & ARV, BE, PLM, PTZ \\
\hline Viscum album L. & 626,915 & muérdago & $P$ & ARV, BE, PLM, PTZ \\
\hline
\end{tabular}

Sapindaceae

Cupania dentata Moc. \& Sessé ex DC.

Paullinia fuscescens Kunth

Paullinia tomentosa Jacq.

Sapindus saponaria L.

Serjania adiantoides Radlk.

Serjania erecta Radlk.

Serjania goniocarpa Radlk.

Serjania mexicana (L.) Willd.

Urvillea ulmacea Kunth

Sapotaceae

Chrysophyllum mexicanum Brandegee

Manilkara zapota (L.) P. Royen

Pouteria sapota (Jacq.) H.E. Moore \& Stearn

Schoepfiaceae

Schoepfia schreberi J.F. Gmel.

Scrophulariaceae

Alonsoa meridionalis (L.f.) Kuntze

Buddleja americana L.

Capraria biflora L.

Capraria frutescens (Mill.) Britten.

Capraria mexicana Moric. ex Benth.
110

46

648

710

492,700

61

970

321

580

cola de iguana

jaboncillo

cola de iguana

1243

657,949

1092

1065

512

1021

47

1071

1024

caimito
chicozapote
zapote mamey

zapote mamey

limoncillo

claudiosa

jarilla
A

B

B

A

B

B

B

B

B
BTP, BTS

BTS, PLM, VSEC

ARV, PLM, VSEC

BTS

ACS, ARV

ACS, ARV

ACS

ACS, ARV, VSEC

BTS, VSEC

BE, BTS, BTP

BE, BTS, BTP

BTP
BTS, BTP

A

ARV

tepozán Ar

PLM.

$\mathrm{H}$

ACS, ARV, BE, BTS, PLM, PTZ, VSEC

$\mathrm{H}$

PTZ, VSEC

PTZ 
Apéndice. Continuación.

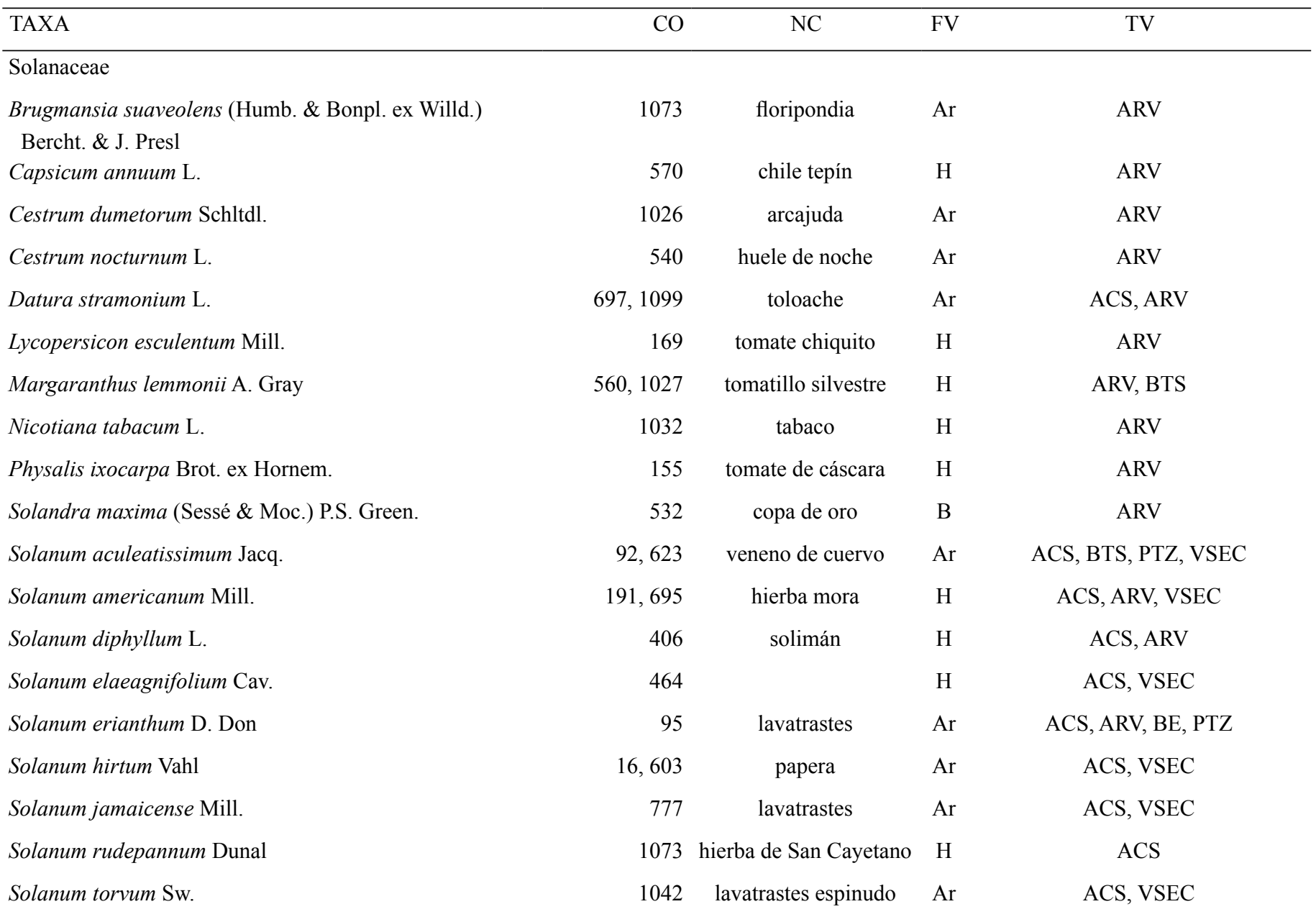

Staphylaceae

Turpinia insignis (Kunth) Tul.

1074

palo verde

A

Tamaricaceae

Tamarix indica Willd.

Urticaceae

Boehmeria cylindrica (L.) Sw.

Cecropia obtusifolia Bertol.

Laportea canadensis (L.) Wedd.

Pilea melastomoides (Poir.) Wedd.

Pilea microphylla (L.) Liebm.

Urtica urens L.

417 tamarindo $\quad$ A $\quad$ ARV

\begin{tabular}{|c|c|c|c|c|}
\hline 182 & chichicastle & $\mathrm{H}$ & ACS, VSEC & \\
\hline 323 & hormiguillo & A & BTP, BTS & \\
\hline 693 & & $\mathrm{H}$ ACS, & ARV, & VSEC \\
\hline 963 & & $\mathrm{H}$ & ACS, VSEC & \\
\hline 261 & & $\mathrm{H}$ & ACS & \\
\hline 421 & chichicastle & $\mathrm{H}$ & ACS, ARV, BTS, V & \\
\hline
\end{tabular}


Apéndice. Continuación.

\begin{tabular}{|c|c|c|c|c|}
\hline TAXA & $\mathrm{CO}$ & $\mathrm{NC}$ & FV & TV \\
\hline \multicolumn{5}{|l|}{ Verbenaceae } \\
\hline Duranta erecta L. & 906 & corona de novia & Ar & ARV \\
\hline Glandularia canadensis (L.) Small & 145 & & $\mathrm{H}$ & ARV \\
\hline Lantana achyranthifolia Desf. & 857 & hierba mariposa & $\mathrm{Ar}$ & ACS, ARV \\
\hline Lantana camara $\mathrm{L}$. & 127,622 & hierba amargosa & $\mathrm{Ar}$ & ACS, BE, BTP, BTS, PLM, PTZ \\
\hline Lantana canescens Kunth & 1154 & hierba de jabillas & Ar & PTZ \\
\hline Lantana hirta Graham & 184 & hierba amargosa & $\mathrm{Ar}$ & BTP, BTS \\
\hline Lantana trifolia $\mathrm{L}$. & 606,1063 & hierba de jabillas & $\mathrm{Ar}$ & ACS, BTS, PTZ, VSEC \\
\hline Lippia alba (Mill.) N.E. Br. ex Britton \& P. Wilson & 704 & lipia & $\mathrm{Ar}$ & $\mathrm{ACS}, \mathrm{ARV}, \mathrm{BE}$ \\
\hline Petrea volubilis $\mathrm{L}$. & 43,707 & bejuco raspa sombrero & $\mathrm{B}$ & BTS, VSEC \\
\hline Phyla stoechadifolia (L.) Small & 730,864 & alfombrilla & $\mathrm{H}$ & ACS, ARV, BE, BTS \\
\hline Priva lappulacea (L.) Pers. & 573 & cadillo de bolsa & $\mathrm{H}$ & BTP, BTS \\
\hline Stachytarpheta jamaicensis (L.) Vahl & 204,659 & rabo de alacrán & $\mathrm{H}$ & ACS, ARV, BE \\
\hline Verbena bipinnatifida Nutt. & 1035 & & $\mathrm{H}$ & VSEC \\
\hline Verbena litoralis Kunth & 1075 & verbena & $\mathrm{H}$ & ARV, BTS, PTZ \\
\hline \multicolumn{5}{|l|}{ Vitaceae } \\
\hline Cissus verticillata (L.) Nicolson \& C.E. Jarvis & 115,708 & tripa de vaca & $\mathrm{B}$ & ACS, BE, BTP, BTS \\
\hline Vitis tiliifolia Humb. \& Bonpl. ex Schult. & 20 & parra & $\mathrm{B}$ & ACS, BE, BTP, BTS \\
\hline
\end{tabular}

